Review

\title{
Bismuth(III) Reagents in Steroid and Terpene Chemistry
}

\section{Jorge A. R. Salvador ${ }^{1}{ }^{*}$, Samuel M. Silvestre ${ }^{2}$ and Rui M. A. Pinto ${ }^{1}$}

1 Laboratório de Química Farmacêutica, Faculdade de Farmácia da Universidade de Coimbra, Pólo das Ciências da Saúde, Azinhaga de Santa Comba, 3000-548, Coimbra, Portugal

2 Health Sciences Research Centre, Faculdade de Ciências da Saúde, Universidade da Beira Interior, Av. Infante D. Henrique, 6201-506 Covilhã, Portugal

* Author to whom correspondence should be addressed; E-Mail: salvador@ci.uc.pt;

Tel.: +351 239488479; Fax: +351 239827126.

Received: 10 February 2011; in revised form: 14 March 2011 / Accepted: 29 March 2011 /

Published: 4 April 2011

\begin{abstract}
Steroid and terpene chemistry still have a great impact on medicinal chemistry. Therefore, the development of new reactions or "greener" processes in this field is a contemporaneous issue. In this review, the use of bismuth(III) salts, as "ecofriendly" reagents/catalysts, on new chemical processes involving steroids and terpenes as substrates will be focused. Special attention will be given to some mechanistic considerations concerning selected reactions.
\end{abstract}

Keywords: bismuth(III) salts; catalysis; steroids; terpenes; triterpenoids

\section{Introduction}

Steroids [1] and terpenes [2] constitute a large and structurally diverse family of natural products and are considered important scaffolds for the synthesis of molecules of pharmaceutical interest. Different contributions ranging from natural product isolation and characterization to the synthesis of new compounds and their biological evaluation are reported every day. These investigations are justified by the well known biological properties of steroids and terpenes that make them useful molecules in pharmacy and medicine.

The literature abounds with classical chemical reactions employed in steroid and terpene chemistry. Despite their wide applicability, these transformations often suffer from disadvantages such as 
handling of toxic, sensitive and/or expensive reagents, difficult work-up procedures, low yields and poor selectivities. Moreover, the lack of catalytic methods to perform a great number of reactions is evident.

The growing relevance of green and sustainable chemistry and the application of its guiding principles to the development of new reactions and chemical processes is changing the face of chemistry [3-7]. Several strategies have been developed for leading to more efficient, sustainable and environmentally friendly chemical processes and products. Among those strategies, catalysis and the design of new processes that avoid the use of toxic reagents have been the subject of intense research. In this context, bismuth(III) salts are suitable reagents for the design of "ecofriendly catalysts", and a large number of methods involving the use of $\mathrm{Bi}$ (III) compounds in organic synthesis have been reported over the last decades [8-22]. Two review papers focusing on the recent advances of bismuth(III) salts usage in organic chemistry, with special emphasis on their application to the synthesis of compounds of pharmaceutical interest have quite recently been published [23,24].

In this review, the use of bismuth(III) salts as reagents and/or catalyst in reactions involving steroids and terpenes as substrates is presented. The review is organized by reaction type with emphasis on the following topics: oxidation reactions, formation and removal of common protecting groups, ringopening of epoxides by nucleophiles, rearrangement reactions and miscellaneous reactions. Particular attention is given to works that highlight what could be called the hidden "Bi" behavior of bismuth. In fact, increasing evidence supports that the catalytic activity of bismuth(III) salts and its hydrates cannot be attributed to single Lewis acid activation of the substrates by bismuth cation, only. Indeed, the observed catalytic activities is thought to be attributable to a subtle balance between each bismuth species of Brønsted and/or Lewis acidic activation [25].

\section{Oxidation Reactions}

\subsection{Oxidation of $\alpha$-hydroxyketones by $\mathrm{Bi}_{2} \mathrm{O}_{3}$}

The use of $\mathrm{Bi}_{2} \mathrm{O}_{3}$, in refluxing acetic acid was found to be an efficient and selective oxidant for the oxidation of $\alpha$-hydroxyketones to the corresponding diones. According to Rigby, the true oxidant is presumably $\mathrm{Bi}(\mathrm{OAc})_{3}$, formed in situ under the reaction conditions, and is subsequently reduced to elemental bismuth (dark powder) [26,27]. This classical and versatile process has been extensively applied in the preparation of various steroids and terpenes, due, mainly, to its chemical selectivity. For example, this method has been useful in the synthesis of 11-hydroxy-12-keto- $\Delta^{9(11)}$-steroids with cholane [28,29], pregnane [30] and androstane [31] backbones. The oxidation of the $\alpha$-hydroxyketone moiety present in ring $\mathrm{A}$ of several steroids with $\mathrm{Bi}_{2} \mathrm{O}_{3} / \mathrm{AcOH}$ was reported as an efficient way to obtain 2-hydroxy-3-keto- $\Delta^{1}$-steroids [32-34]. A different reactivity was observed in the $\mathrm{Bi}_{2} \mathrm{O}_{3} / \mathrm{AcOH}$ oxidation of the 20,21-ketol group of a 21-chloromethyl-pregnane derivative resulted in the formation of a dehydrohalogenated 20,21-diketo product, in 52\% yield (Scheme 1) [35]. 
Scheme 1. $\mathrm{Bi}_{2} \mathrm{O}_{3} / \mathrm{AcOH}$ oxidation of the 20,21-ketol group of a 21-chloromethylpregnane derivative.<smiles>CC(C)(C)O[Mg]O[Mg]</smiles><smiles>CC(=O)C(=O)[C@]1(O)CCC2C3CCC4=CC(=O)C=C[C@]4(C)[C@H]3[C@H](O)C[C@]21C</smiles>

The $\mathrm{Bi}_{2} \mathrm{O}_{3} / \mathrm{AcOH}$ system has been applied to the preparation of an intermediate in the synthesis of cortisone starting from hecogenin, since under this reaction conditions the labile spirostan side chain remained intact (Scheme 2) [28,29].

Scheme 2. $\mathrm{Bi}_{2} \mathrm{O}_{3} / \mathrm{AcOH}$ oxidation of the 11-keto-12 $\beta$-hydroxy moiety of a hecogenin derivative.

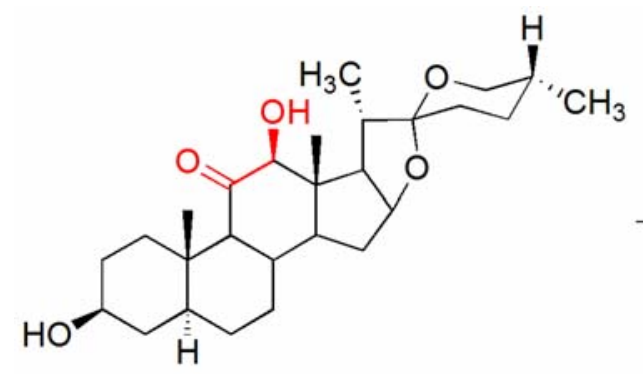
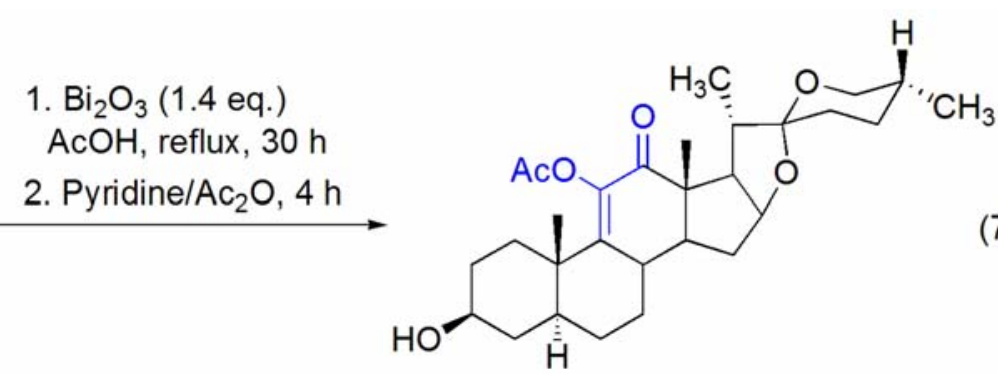

The triterpene alkaloid cevine, bearing a hemiacetal function, was converted into a 5-membered ring A hydroxy- $\delta$-lactone product by treatment with the $\mathrm{Bi}_{2} \mathrm{O}_{3} / \mathrm{AcOH}$ system (Scheme 3) [36] Similarly, the conversion of the related triterpenes veracevine and cevagenine into similar hydroxy- $\delta$ lactone derivatives was also reported by Kupchan and Lavie [36].

Scheme 3. $\mathrm{Bi}_{2} \mathrm{O}_{3} / \mathrm{AcOH}$ oxidation of cevine.

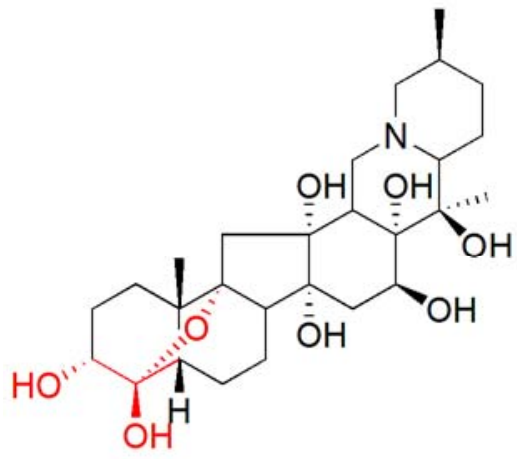

Cevine

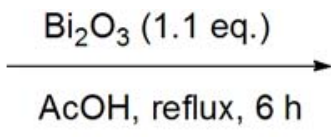

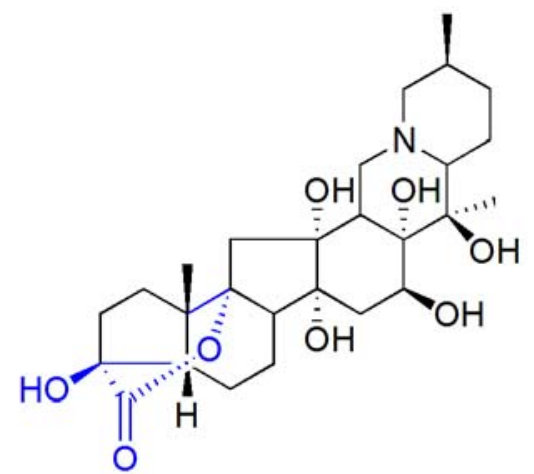

$(46 \%)$

Other examples of the application of this $\mathrm{Bi}_{2} \mathrm{O}_{3} / \mathrm{AcOH}$ system include the final step in the synthesis of diosphenolene [37], the preparation of $\alpha$-diketo intermediate during the total synthesis of the racemate of aphidicolin [38] and the oxidation the $\alpha$-hydroxyketone functionality present in ring A of highly oxygenated tetracyclic triterpenes, such as cucurbitacin D [39] and cucurbitacin B [40]. More 
recently, during the total synthesis of bruceantin, the $\mathrm{Bi}_{2} \mathrm{O}_{3} / \mathrm{AcOH}$ system was applied to the oxidation of an $\alpha$-hydroxy ketone intermediate to afford the corresponding diosphenol, in $72 \%$ yield (Scheme 4) [41].

Scheme 4. $\mathrm{Bi}_{2} \mathrm{O}_{3} / \mathrm{AcOH}$ oxidation of an intermediate for the synthesis of bruceantin.

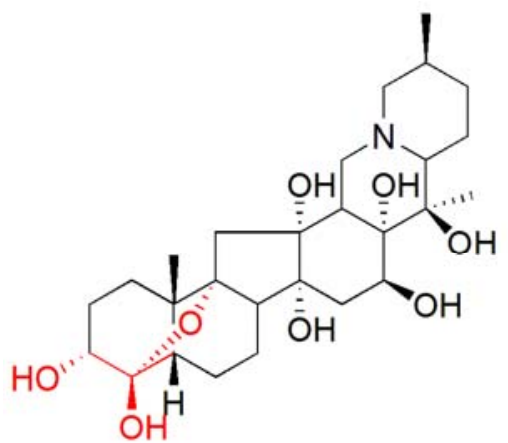

Cevine
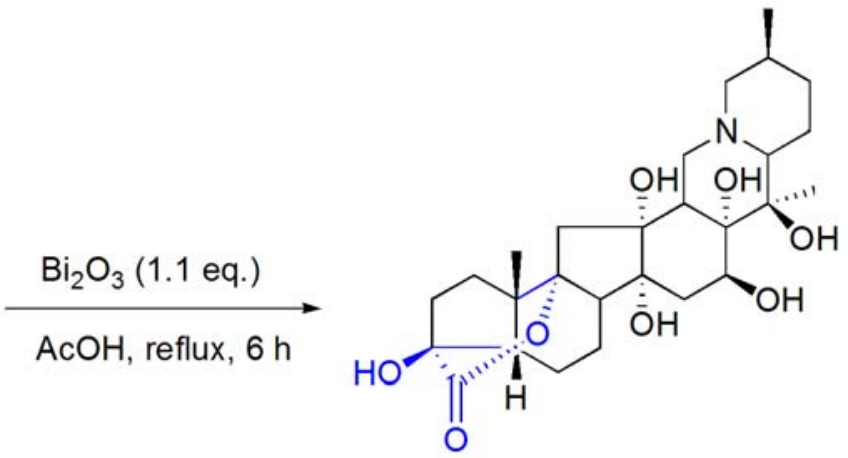

\subsection{Allylic oxidation}

The allylic oxidation of $\Delta^{5}$-steroids $[42,43]$ using several homogeneous or heterogeneous bismuth catalysts in combination with $t$ - $\mathrm{BuOOH}$ has been recently reported $[44,45] . \mathrm{BiCl}_{3}$ was found to be the best catalyst and several $\Delta^{5}$-steroids were converted into the corresponding $\Delta^{5}$-7-oxosteroids in good to high yields (Scheme 5). The $\mathrm{BiCl}_{3} / t$ - $\mathrm{BuOOH}$ system proved to be very selective for this reaction, since significant epoxidation of the double bond, secondary hydroxyl group oxidation (Scheme 5, reaction 2) or cleavage of the diosgenin side chain were not observed.

Scheme 5. Bismuth (III) salt-catalyzed allylic oxidation of $\Delta^{5}$-steroids.

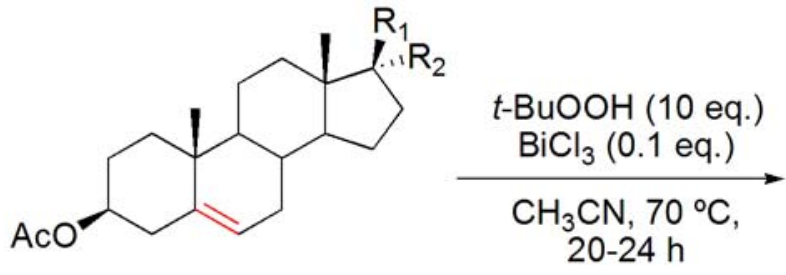
$20-24 \mathrm{~h}$

$\mathrm{R}_{1}=\mathrm{C}_{8} \mathrm{H}_{17}$ or $\mathrm{COCH}_{3}$ and $\mathrm{R}_{2}=\mathrm{H}$

$\mathrm{R}_{1}, \mathrm{R}_{2}=\mathrm{O}$ or spiroketal side chain<smiles>C[C@]12CCC3C(CC=C4C[C@H](O)CC[C@@]43C)C1CCC2=O</smiles><smiles>[R2]C1CCC2C3C(=O)C=C4CC(OC(C)=O)CCC4(C)C3CCC12C</smiles>

$(60-88 \%)$

Moreover, a white insoluble solid was formed during the $\mathrm{BiCl}_{3}$-catayzed reactions. This solid was recovered by filtration and identified by X-ray diffraction (XRD) analysis as $\mathrm{BiOCl}$. Thus, $\mathrm{BiCl}_{3}$ can 
be recovered at the end of the reaction and reused as $\mathrm{BiOCl}$, which is also active under these reaction conditions, or reconverted again into $\mathrm{BiCl}_{3}$.

Under similar reaction conditions, the allylic oxidation of $(+)$-valencene was reported and the corresponding $\alpha, \beta$-unsaturated ketone, nootkatone, was obtained in 35\% yield (Scheme 6) $[44,45]$.

Scheme 6. Bismuth (III) salt-catalyzed allylic oxidation of (+)-valencene.
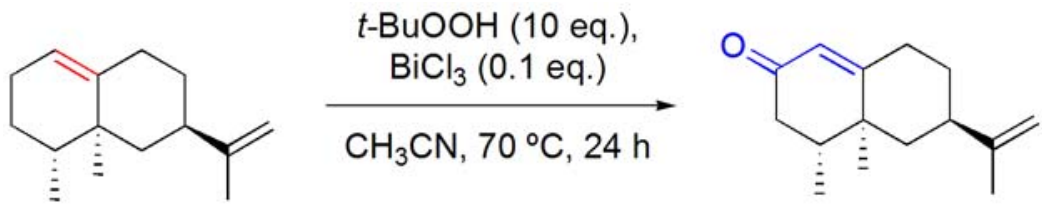

\subsection{Oxidation of alcohols}

Considering the excellent chemoselectivity observed in the allylic oxidation of dehydroepiandrosterone (Scheme 5, reaction 2), it was interesting to evaluate the selective allylic alcohol oxidation in the presence of a secondary saturated hydroxyl group using the $\mathrm{BiCl}_{3} / t$ - $\mathrm{BuOOH}$ system. This study was performed using androst-4-ene-3 $\beta, 17 \beta$-diol and it was observed that after complete consumption of this substrate, the important steroid hormone testosterone could be obtained, in $45 \%$ yield, after flash column chromatography (Scheme 7) [46].

Scheme 7. Selective allylic alcohol oxidation of androst-4-ene-3 $\beta, 17 \beta$-diol by the $\mathrm{BiCl}_{3} / t$ $\mathrm{BuOOH}$ system.
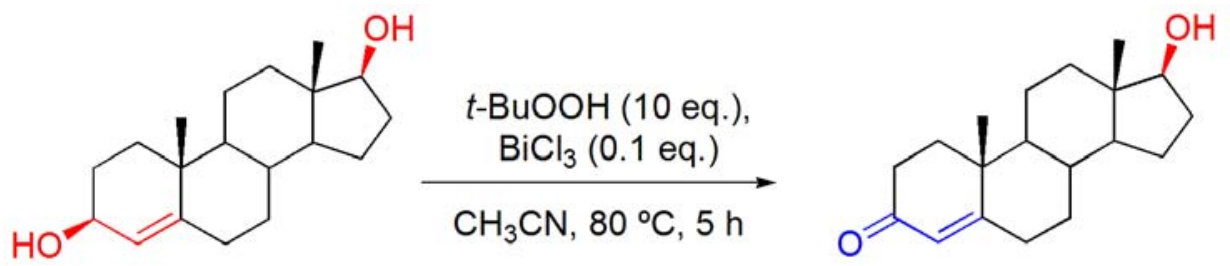

In another study, the oxidation of the allylic alcohol moiety of carveol has been effected with montmorillonite impregnated with $\mathrm{Bi}\left(\mathrm{NO}_{3}\right)_{3} \cdot 5 \mathrm{H}_{2} \mathrm{O}$ affording carvone, a naturally occurring monoterpene (Scheme 8) [47].

Scheme 8. Oxidation of carveol with montmorillonite impregnated with $\mathrm{Bi}\left(\mathrm{NO}_{3}\right)_{3} \cdot 5 \mathrm{H}_{2} \mathrm{O}$.<smiles>C=C(C)C1CC=C(C)C(O)C1</smiles>

Carveol

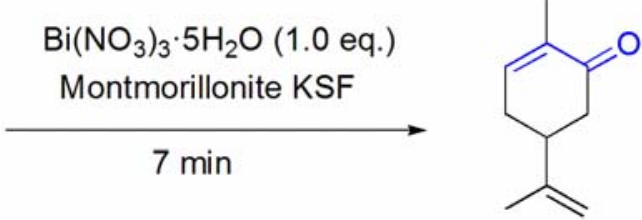

Carvone 


\section{Formation of Common Protecting Groups}

\subsection{Acylation of alcohols}

The conversion of cholesterol and cholesterol formate into the corresponding $3 \beta$-acetoxy derivative has been described by Reese and co-workers using stoichiometric amounts of $\mathrm{Bi}(\mathrm{OAc})_{3}$ (Scheme 9, reaction 1) [48].

More recently, acylation procedures using bismuth(III) salts as catalysts have been reported, and the acetylation of cholesterol was performed using $\mathrm{Bi}(\mathrm{OTf})_{3} \cdot \mathrm{xH}_{2} \mathrm{O}$ in the presence of acetic anhydride (Scheme 9, reaction 2) [49,50]. Remarkably, all the three hydroxyl groups of cholic acid methyl ester were converted to the corresponding acetoxy groups in excellent yield, regardless of the sterically hindered $12 \alpha$-hydroxy group $[49,50]$.

Scheme 9. Different procedures for the acylation of cholesterol and menthol using bismuth(III) salts.
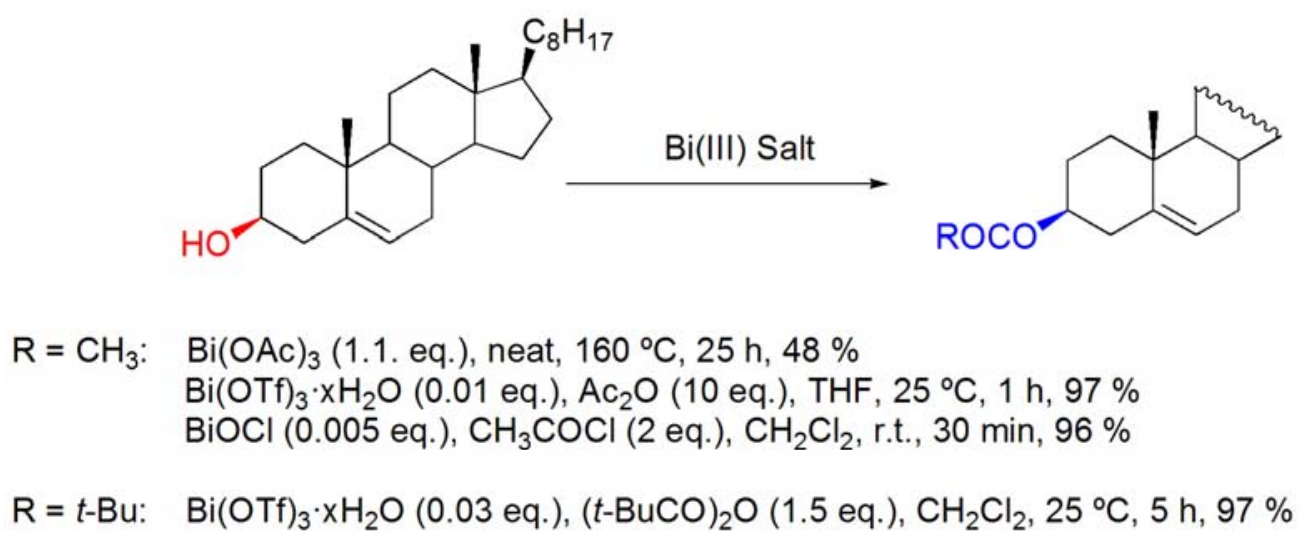

$\mathrm{R}=t-\mathrm{Bu}: \quad \mathrm{Bi}(\mathrm{OTf})_{3} \cdot \mathrm{xH}_{2} \mathrm{O}$ (0.03 eq.), ( $\left.t-\mathrm{BuCO}\right)_{2} \mathrm{O}$ (1.5 eq.), $\mathrm{CH}_{2} \mathrm{Cl}_{2}, 25^{\circ} \mathrm{C}, 5 \mathrm{~h}, 97 \%$
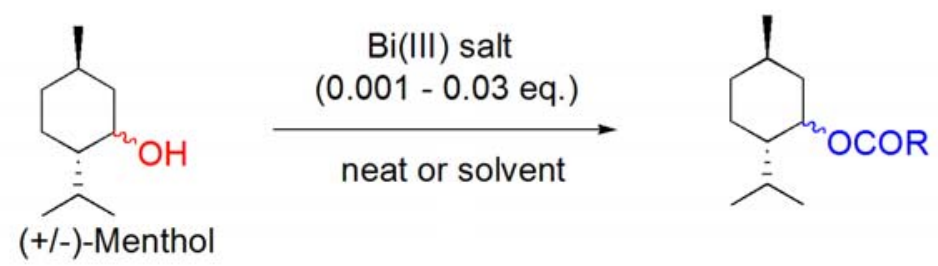

$$
\begin{array}{ll}
\mathrm{R}=\mathrm{H}: & \mathrm{HCO}_{2} \mathrm{Et}, \text { neat, reflux, } 60-75 \mathrm{~min}, 75-95 \% \\
\mathrm{R}=\mathrm{CH}_{3}: & \begin{array}{l}
\mathrm{Ac}_{2} \mathrm{O}(1.5-10 \text { eq. }), \text { r.t.-reflux, } 20 \mathrm{~min}-1.5 \mathrm{~h}, 87-97 \% \\
\mathrm{BiOCl} / \mathrm{CH}_{3} \mathrm{COCl}, \text { r.t., } 5 \mathrm{~min}, 93 \%
\end{array} \\
\mathrm{R}=t-\mathrm{Bu}: & (t-\mathrm{BuCO})_{2} \mathrm{O}, \text { r.t., } 4 \mathrm{~h}, 93 \% \\
\mathrm{R}=\mathrm{Ph}: & (\mathrm{PhCO})_{2}, \text { r.t., } 45-60 \mathrm{~min}, 90-95 \%
\end{array}
$$

The $\mathrm{Ac}_{2} \mathrm{O} / \mathrm{Bi}(\mathrm{OTf})_{3} \cdot \mathrm{xH}_{2} \mathrm{O}$ system has been applied to the acetylation of several monooxygenated monoterpenes, such as geraniol [49,50], borneol [49,50], linalool [49,50] and menthol (Scheme 9, reaction 6 [50,51-53]. $\mathrm{BiCl}_{3}$ and $\mathrm{Bi}\left(\mathrm{CF}_{3} \mathrm{COO}\right)_{3}$ were also reported as efficient catalysts for the 
acetylation of menthol [52,53], however higher temperatures and/or reaction times were needed to achieve yields identical to those obtained with $\mathrm{Bi}(\mathrm{OTf})_{3} \cdot \mathrm{xH}_{2} \mathrm{O}$.

A very efficient process for the acetylation of cholesterol (Scheme 9, reaction 3) [54] and menthol (Scheme 9, reaction 7), among several other alcohols, using in situ generated $\mathrm{BiCl}_{3}$ from the procatalyst $\mathrm{BiOCl}$ and acetyl chloride was also described.

The pivaloylation of cholesterol (Scheme 9, reaction 4), borneol and menthol (Scheme 9, reaction 8) was accomplished by Orita and co-workers using $\mathrm{Bi}(\mathrm{OTf})_{3} \cdot \mathrm{xH}_{2} \mathrm{O}(3 \mathrm{~mol} \%)$ in the presence of either pivaloic anhydride or pivaloyl chloride [50].

Menthol was quantitatively converted into the corresponding formate and benzoate derivatives after reaction with ethyl formate [53] and benzoic anhydride [52], respectively, in the presence of $\mathrm{BiCl}_{3}$, $\mathrm{Bi}(\mathrm{TFA})_{3}$ or $\mathrm{Bi}(\mathrm{OTf})_{3} \cdot \mathrm{xH}_{2} \mathrm{O}$ (Scheme 9, reactions 5 and 9). Bismuth(III) salts catalyzed the direct conversion of the THP ether of menthol to the corresponding formate, acetate and benzoate derivatives by reaction with appropriate acylation reagents (Scheme 10). The reactions proceeded at reflux with ethyl formate or acetic acid [55], whereas the use of acetic or benzoic anhydrides, at room temperature, was enough to achieve high yields with short reaction times (Scheme 10) [56].

Scheme 10. Bismuth(III) salt-catalyzed transformations of the THP ether of (-)-menthol to the corresponding formate, acetate and benzoate derivatives.

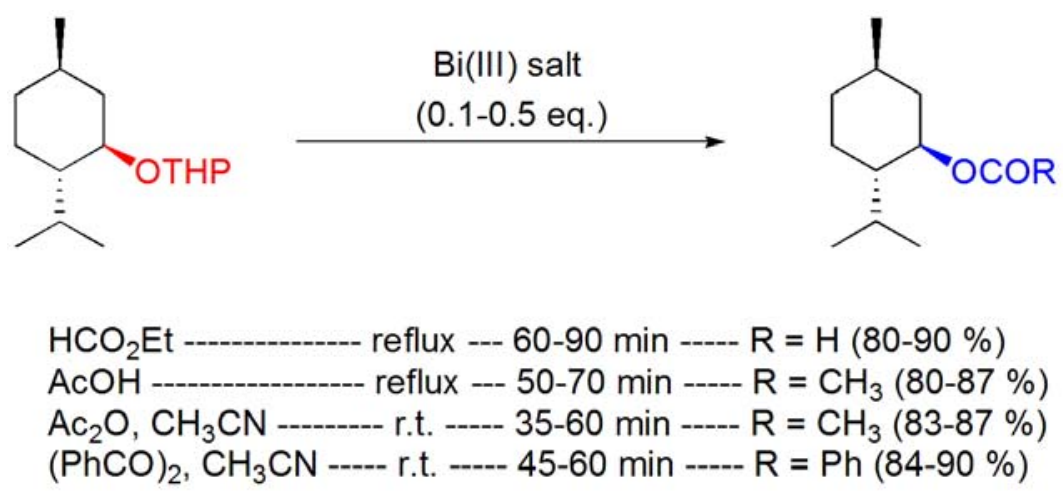

An interesting transesterification of betulin with ethyl acetate has been recently reported, using $\mathrm{Bi}(\mathrm{OTf})_{3} \cdot \mathrm{xH}_{2} \mathrm{O}$ as catalyst. Betulin-28-yl acetate was obtained as major reaction product along with allobetulin, resulting from the $\mathrm{Bi}(\mathrm{OTf})_{3} \cdot \mathrm{xH}_{2} \mathrm{O}$-catalyzed Wagner-Meerwein rearrangement (Scheme 11) $[57]$.

Scheme 11. Transesterification of betulin with ethyl acetate catalyzed by $\mathrm{Bi}(\mathrm{OTf})_{3} \cdot \mathrm{xH}_{2} \mathrm{O}$.
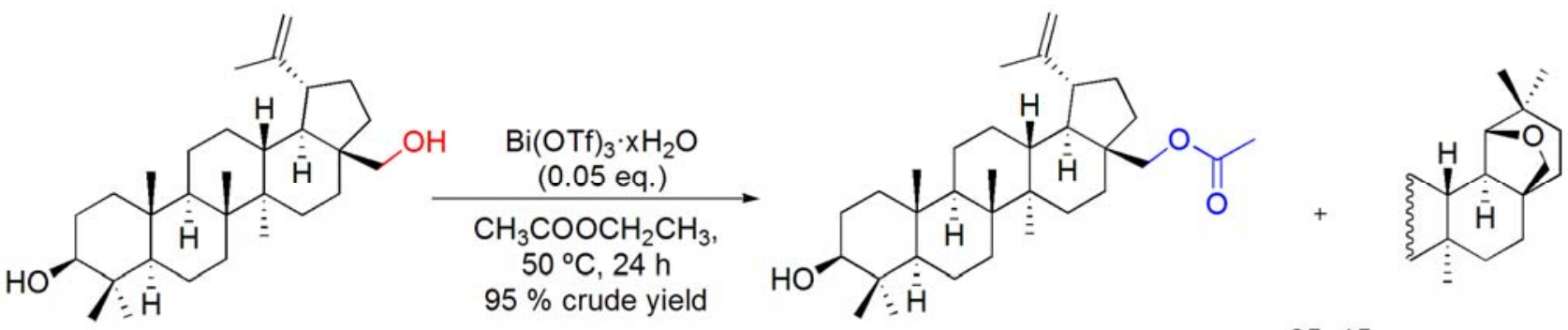


\subsection{Formation of ethers}

The tetrahydropyranylation of the secondary hydroxyl groups of cholesterol (Scheme 12, reaction 1), geraniol and (-)-menthol and (Scheme 12, reaction 2) and the tertiary alcohol of linalool has been accomplished by reaction with 3,4-dihydro-2H-pyran (DHP) in the presence of $0.1 \mathrm{~mol} \%$ of $\mathrm{Bi}(\mathrm{OTf})_{3} \cdot \mathrm{xH}_{2} \mathrm{O}$ [58]. More recently, $\mathrm{Bi}\left(\mathrm{NO}_{3}\right)_{3} \cdot 5 \mathrm{H}_{2} \mathrm{O}$ was reported to be a more efficient catalyst, affording the tetrahydropyranyl (THP) ethers of menthol (Scheme 12, reaction 3) and geraniol in high yield, in shorter reaction times [59].

Scheme 12. Bismuth(III) salt-catalyzed tetrahydropyranylation of cholesterol and menthol.
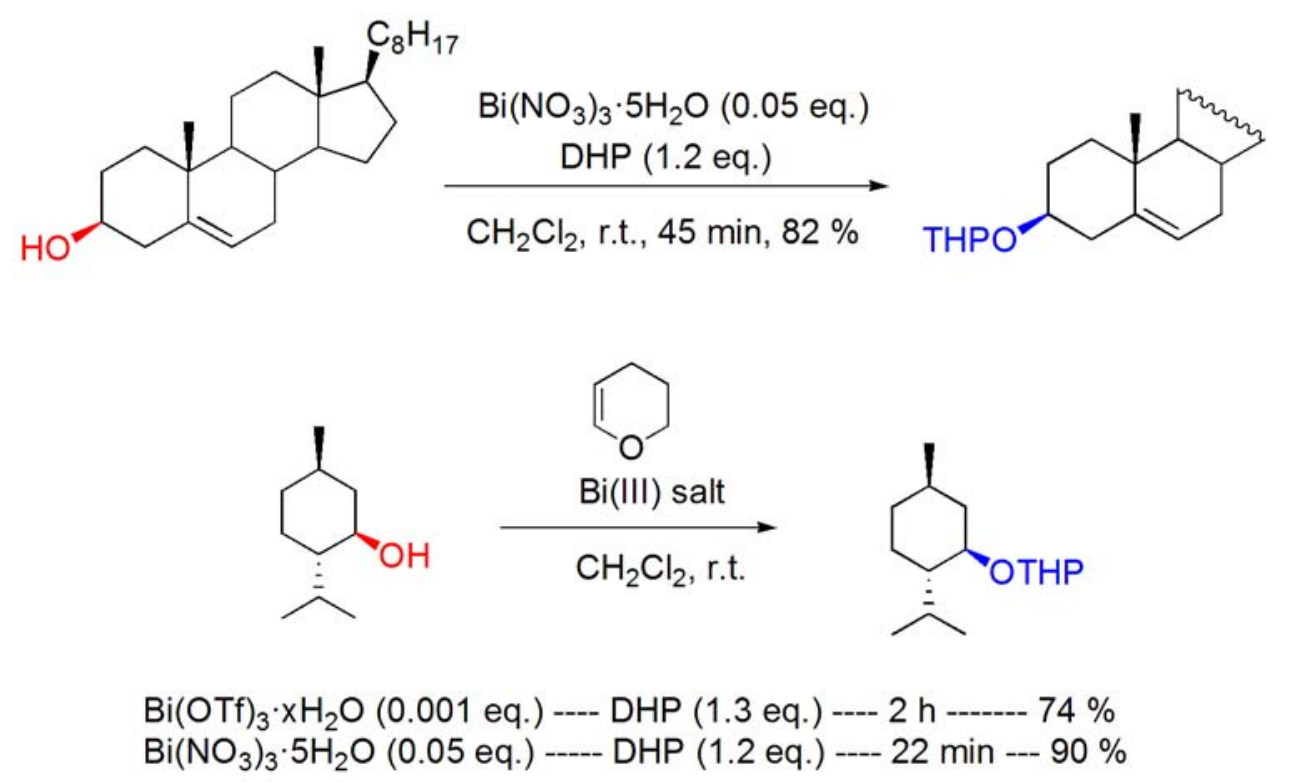

Keramane and co-workers reported the benzylation of (S)-(-)-menthol with racemic 1phenylethanol in the presence of catalytic amounts of $\mathrm{BiBr}_{3}[60]$. The reaction was performed using the toxic $\mathrm{CCl}_{4}$ as solvent and the corresponding ether was obtained as an equimolar mixture of diastereomers in $90 \%$ yield (Scheme 13), and thus the reaction was shown to occur specifically with retention of configuration.

Scheme 13. $\mathrm{BiBr}_{3}$-catalyzed benzylation of $(S)-(-)$-menthol.

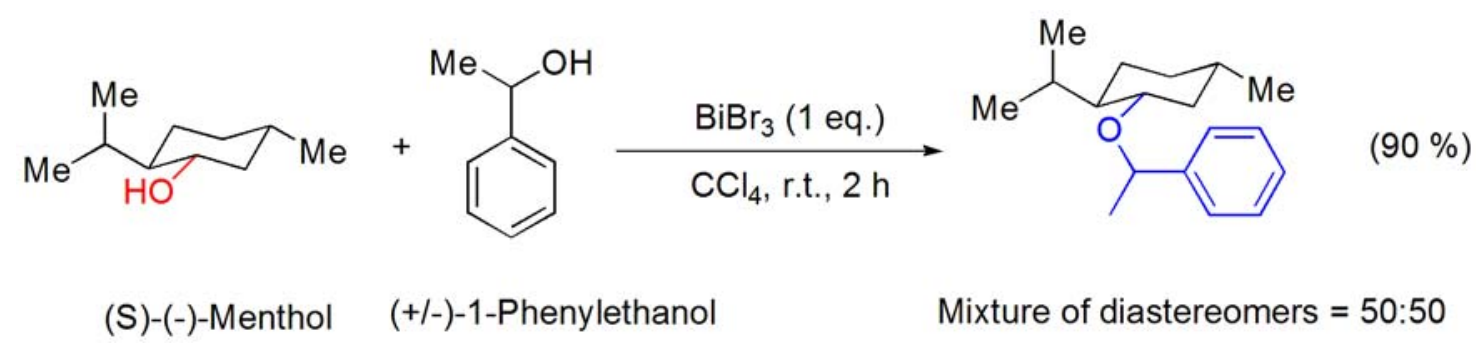

Very recently, a mild and efficient solvent-free method for the silylation of alcohols and phenols with hexamethyldisilazane (HDMS) and $\mathrm{Bi}(\mathrm{OTf})_{3} \cdot \mathrm{xH}_{2} \mathrm{O}$ as catalyst was reported. This process was 
successfully applied to geraniol, an acid sensitive alcohol with two double bonds, and the corresponding trimethylsilyl ether (TMS) was prepared in 95\% yield, after just 5 min. of reaction [61].

\section{Removal of Common Protecting Groups}

\subsection{Deprotection of $O, O$-acetals}

The deprotection of citral dimethylacetal has been performed in the presence of $0.1 \mathrm{~mol} \%$ of $\mathrm{Bi}(\mathrm{OTf})_{3} \cdot \mathrm{xH}_{2} \mathrm{O}$ using $\mathrm{THF} / \mathrm{H}_{2} \mathrm{O}(4: 1 \mathrm{v} / \mathrm{v})$ as solvent (Scheme 14, reaction 1) [62]. More recently, the same reaction has also been reported with $\mathrm{BiI}_{3}\left(1 \mathrm{~mol} \%\right.$ ) in $\mathrm{H}_{2} \mathrm{O}$ (Scheme 14, reaction 2) [63].

Scheme 14. Bismuth(III) salt-catalyzed deprotection of citral dimethylacetal.

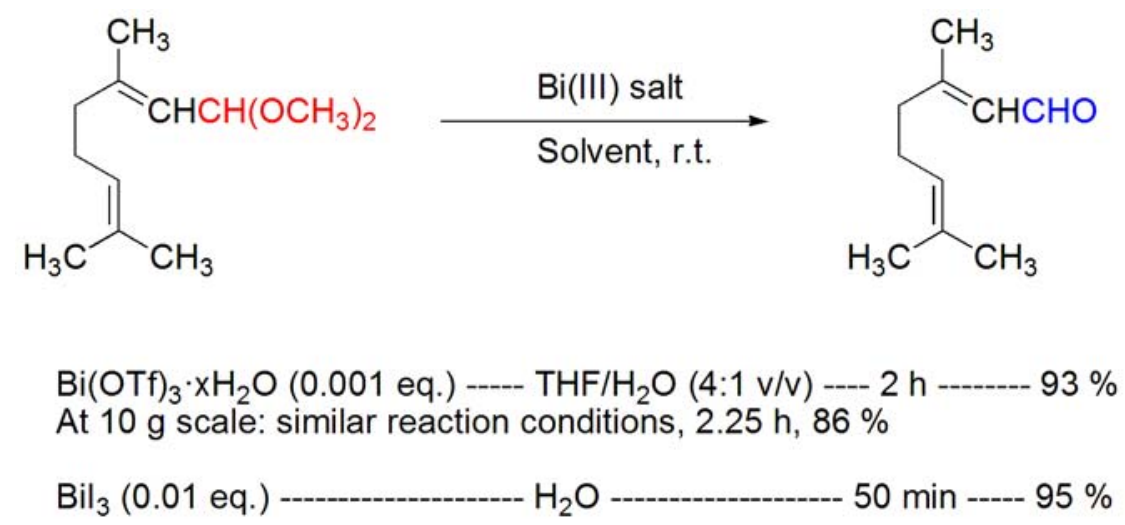

\subsection{Deprotection of ether groups}

The high yielding depyranylation reactions of geraniol, menthol and linalool THP ether derivatives have been reported using $1 \mathrm{~mol} \% \mathrm{Bi}(\mathrm{OTf})_{3} \cdot \mathrm{xH}_{2} \mathrm{O}$ in DMF-MeOH $(9: 1 \mathrm{v} / \mathrm{v})$ [58] or $\mathrm{BiCl}_{3}(3 \mathrm{~mol} \%)$, $\mathrm{Bi}(\mathrm{TFA})_{3}(5 \mathrm{~mol} \%)$ and $\mathrm{Bi}(\mathrm{OTf})_{3} \cdot \mathrm{xH}_{2} \mathrm{O}(1 \mathrm{~mol} \%)$ in $\mathrm{MeOH}$ (Scheme 15) [64].

Scheme 15. Bismuth(III) salt-catalyzed depyranylation reaction of (-)-menthol THP ether.
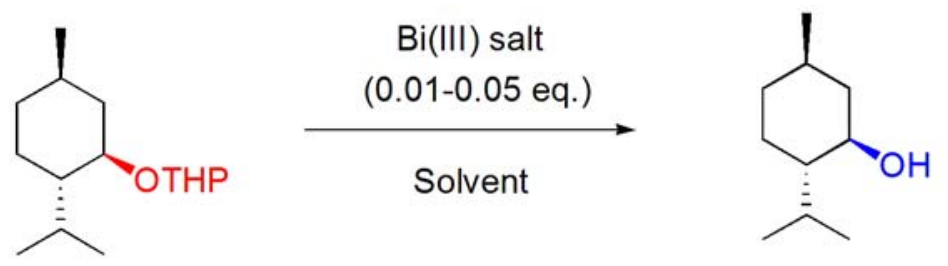

$(83-98 \%)$

The deprotection of the tert-butyldimethylsilyl ether of (-)-menthol was accomplished using the $\mathrm{BiCl}_{3} / \mathrm{NaI}$ system in acetonitrile, at room temperature, in $80 \%$ yield, without loss of the original configuration (Scheme 16) [65]. 
Scheme 16. Deprotection of the tert-butyldimethylsilyl ether of (-)-menthol by the $\mathrm{BiCl}_{3} / \mathrm{NaI}$ system.
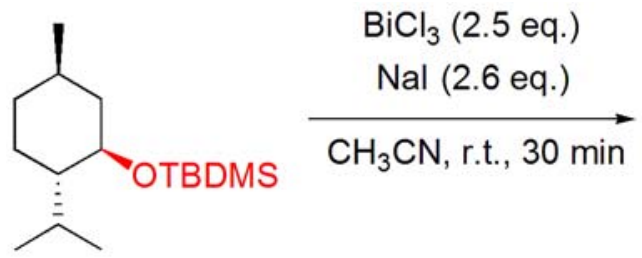

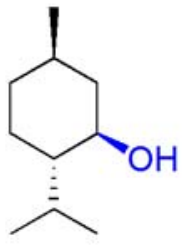

$(80 \%)$

(-)-Menthol

\subsection{Deprotection of oximes to carbonyl compounds}

A catalytic procedure using $10 \mathrm{~mol} \%$ of $\mathrm{BiCl}_{3}$, in $\mathrm{THF}$, under microwave irradiation, was reported for the regeneration of carbonyl groups from their oximes. The methodology was applied to $5 \alpha-$ cholestan-3-one oxime and the corresponding 3-keto-steroid was obtained in $80 \%$ yield (Scheme 17) [66].

Scheme 17. $\mathrm{BiCl}_{3}$-catalyzed conversion of $5 \alpha$-cholestan-3-one oxime to the parent 3 -keto-steroid.

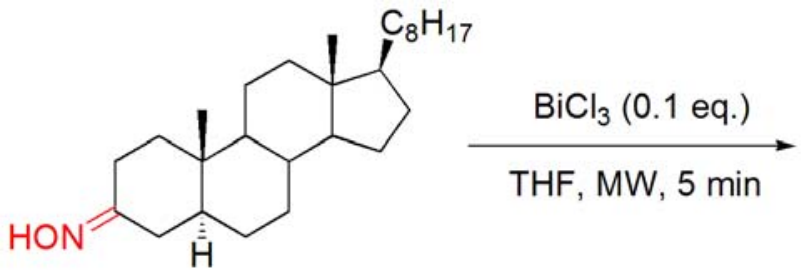

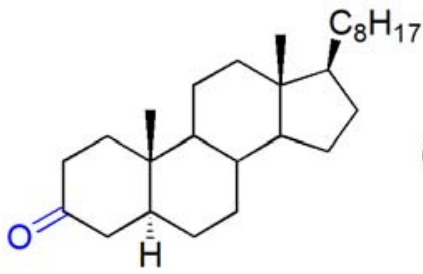

\section{Nucleophilic Ring-opening of Epoxides}

\subsection{Ritter reaction of epoxides}

The Ritter reaction of $5 \alpha, 6 \alpha$ - and $5 \beta, 6 \beta$-epoxysteroids with nitriles in the presence of bismuth(III) salts was reported to give the corresponding vic-acylamino-hydroxy products, in high yields (Scheme 18) [67-69]. This process was stereo- and regioselective as the result of the trans-diaxial ring-opening of the epoxysteroids. In the presence of several other functional groups, such as hydroxyl, ketone or ester, the reaction occurred selectively at the epoxide group. Interestingly, a quite recent study using DFT calculation showed that the higher affinity of $\mathrm{Bi}$ for $\mathrm{Br}$ can prevent side reactions [70] and makes $\mathrm{BiBr}_{3}$ a better Lewis acid catalyst, which is in accordance with the better results achieved with $\mathrm{BiBr}_{3}$ in this Ritter reaction, when compared with $\mathrm{BiCl}_{3}$.

During the study of the bismuth(III)-promoted Ritter reaction of epoxides, the conversion of (-)caryophyllene oxide into a clovan-9-ol derivative bearing a $2 \beta$-acetamide group at ring A was reported (Scheme 19) [67]. Despite the low yield (33\%), this reaction is an alternative approach for the synthesis of clovane-type compounds with nitrogen atoms directly attached to C-2. 
Scheme 18. $\mathrm{BiBr}_{3}$-catalyzed Ritter reaction of epoxysteroids.

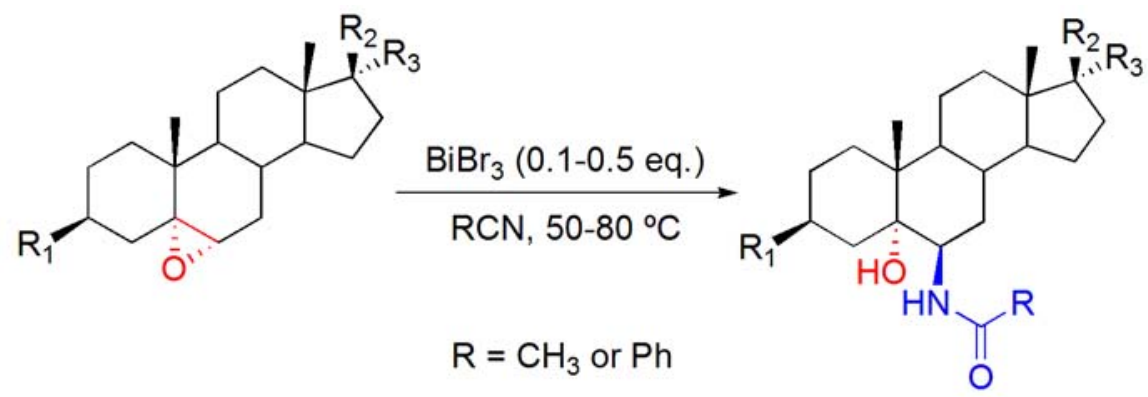

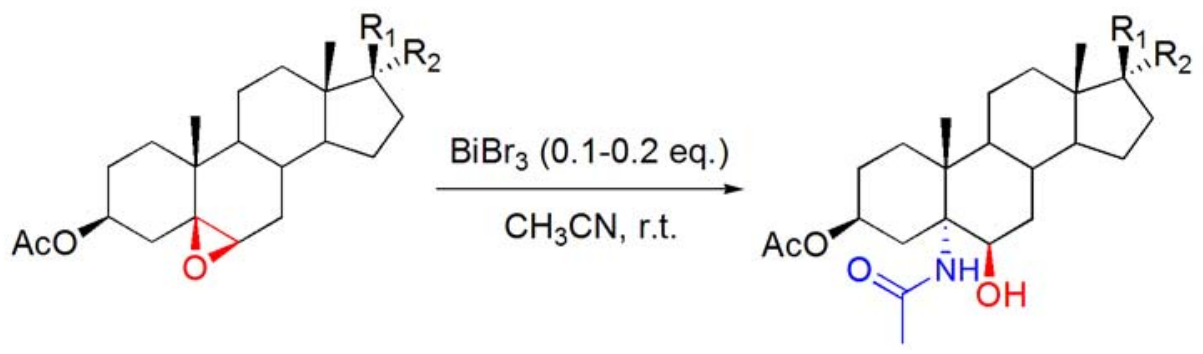

Scheme 19. $\mathrm{BiBr}_{3}$-catalyzed Ritter reaction of (-)-caryophyllene oxide.

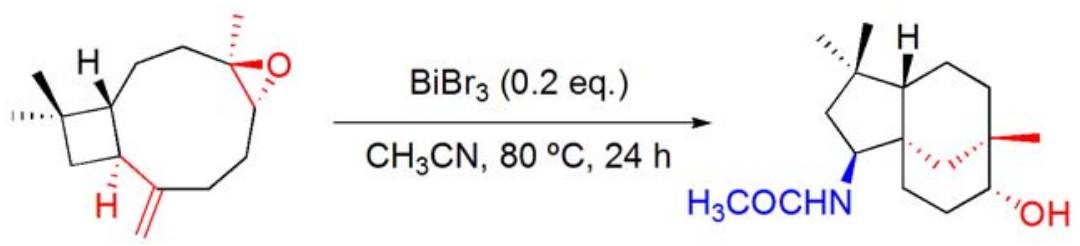

\subsection{Ring opening of epoxides with bismuth(III) salt}

The Ritter reaction of epoxysteroids was found to occur under catalytic and stoichiometric conditions with $\mathrm{BiBr}_{3}$ [67] However, when stoichiometric amounts of $\mathrm{BiCl}_{3}$ or $\mathrm{Bi}\left(\mathrm{NO}_{3}\right)_{3} \cdot 5 \mathrm{H}_{2} \mathrm{O}$ were used to promote the Ritter reaction in acetonitrile, a competitive side product was detected, in both cases. These products were found to be the result of the epoxide ring-opening by $\mathrm{BiCl}_{3}$ and $\mathrm{Bi}\left(\mathrm{NO}_{3}\right)_{3} \cdot 5 \mathrm{H}_{2} \mathrm{O}$, respectively [71]. Thus, using stoichiometric amounts of bismuth(III) salts, such as $\mathrm{BiCl}_{3}, \mathrm{BiBr}_{3}$ or $\mathrm{Bi}\left(\mathrm{NO}_{3}\right)_{3} \cdot 5 \mathrm{H}_{2} \mathrm{O}$, and, simply, by changing the solvent to 1,4-dioxane, halohydrins and $\beta$-hydroxy-nitrates could be obtained in high yields by ring-opening of $5 \alpha, 6 \alpha-, 5 \beta, 6 \beta$ - and $2 \alpha, 3 \alpha-$ epoxysteroids (Scheme 20) [71-73].

The reactions were also stereo-, regio- and chemoselective. Notably, the ring opening of a $5 \alpha, 6 \alpha ; 16 \alpha, 17 \alpha$-diepoxysteroid proved to be highly specific for the $5 \alpha, 6 \alpha$-epoxide group (Scheme 20, reaction 3) [71,73]. In order to understand the nature of the nucleophilic species, the reaction was performed in the presence of 2,6-di-t-butylpyridine (2,6-DTBP), a known proton scavenger which only binds to protons and is unable to coordinate to metal ions due to the bulky $t$-butyl groups [74]. Thus, in these reaction conditions, both $\mathrm{BiCl}_{3}$ and $\mathrm{Bi}\left(\mathrm{NO}_{3}\right)_{3} \cdot 5 \mathrm{H}_{2} \mathrm{O}$ were able to afford the corresponding $\beta$ hydroxy substituted products, in a shorter reaction time than when the reaction was performed without 2,6-DTBP [71]. Taking into account the mechanism proposed by Keramane and co-workers for the chlorination of alcohols with $\mathrm{BiCl}_{3}$ [75] and a recent DFT work that studied the Lewis acidity of $\mathrm{BiX}_{3}$ 
( $\mathrm{X}=\mathrm{Cl}, \mathrm{Br}$ and $\mathrm{I}$ ) towards alcohols [70], it has been suggested that the ring opening reaction is mediated by the Lewis acidity of bismuth towards the epoxide (Scheme 21). As suggested by Keramane et al., a new bismuth species should be formed (" $\mathrm{BiCl}_{2} \mathrm{OH}$ ") [75]. In the ring opening of epoxides, one molecule of $\mathrm{H}_{2} \mathrm{O}$, participates by furnishing a $\mathrm{H}^{+}$, present in the final hydroxyl group, whereas the $\mathrm{OH}^{-}$will act as the third ligand of the newly formed bismuth species. Stabilization of Bi$\mathrm{O}$ complex or the final " $\mathrm{BiCl}_{2} \mathrm{OH}$ " by 2,6-DTBP may help to explain the higher reaction rate observed in the reactions performed in the presence of this organic base.

Scheme 20. Ring opening of epoxysteroids with $\mathrm{BiX}_{3}\left(\mathrm{X}=\mathrm{Cl}, \mathrm{Br}\right.$ and $\left.\mathrm{ONO}_{2}\right)$.

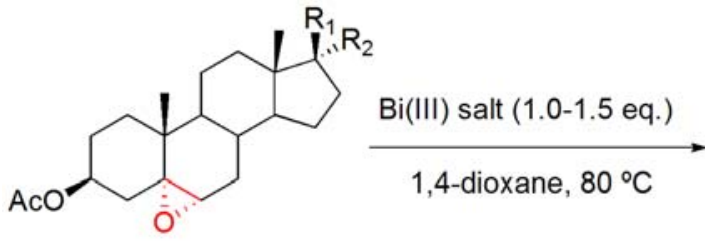

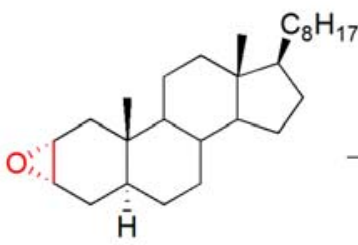<smiles>[R16]C1CCC2C3CC([X])C4(C)CCC(OC(C)=O)CC4(C)C3CCC12C</smiles>

$\mathrm{X}=\mathrm{Cl}, \mathrm{Br}, \mathrm{ONO}_{2}$

$(88-93 \%)$<smiles>CCCCCCCCC1CCC2C3CCC4C[C@H](O)C(Cl)CC4(C)C3CCC12C</smiles>

$(92 \%)$

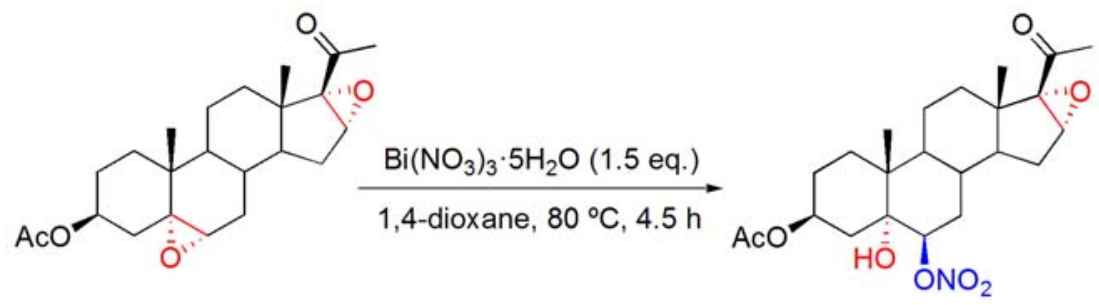

Scheme 21. Possible mechanism for the ring opening of epoxysteroids with $\mathrm{BiX}_{3}(\mathrm{X}=\mathrm{Cl}$, $\mathrm{Br}$ and $\mathrm{ONO}_{2}$ ).

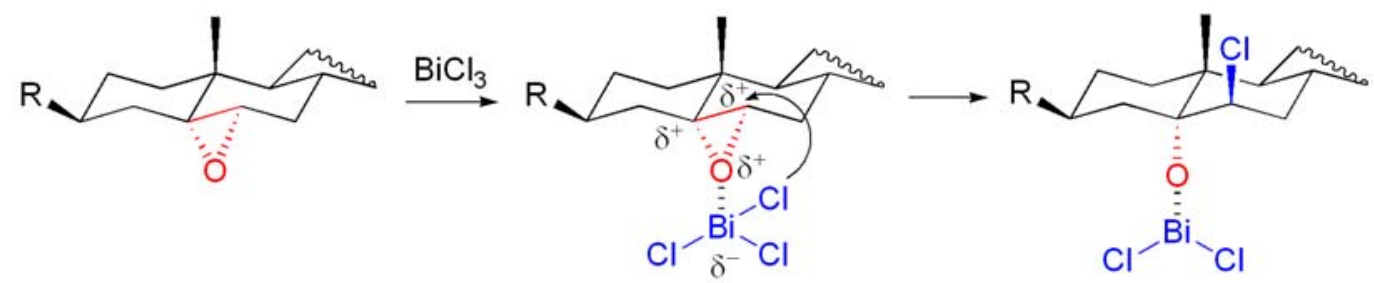

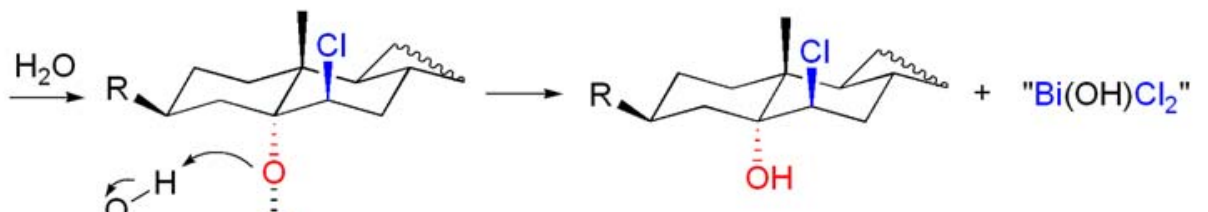

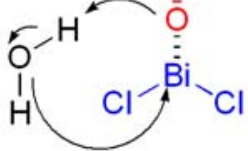




\subsection{Trans-diaxial hydroxylation of $\Delta^{5}$-steroids}

Taking into account a recent report for the epoxidation of $\Delta^{5}$-steroids by the use of MMPP [76] and the previous knowledge of bismuth-catalyzed ring-opening reactions of epoxysteroids [67,71], Carvalho et al. described a fast and efficient high-yielding sequential approach for the preparation of $5 \alpha, 6 \beta$-dihydroxysteroids using $\Delta^{5}$-steroids as raw materials [77]. This new synthetic protocol involves two steps: (i) formation of the epoxide from $\Delta^{5}$-steroids, using MMPP as oxidant; and (ii) trans-diaxial ring opening of the diastereomeric mixture of $5 \alpha, 6 \alpha$ - and $65,6 \beta$-epoxides with $\mathrm{Bi}(\mathrm{OTf})_{3} \cdot \mathrm{xH}_{2} \mathrm{O}$ in acetone. A catalytic ring-opening of the epoxide was achieved when a filtration was performed to remove the insoluble salts formed in the first step (Scheme 22) [77]. With this methodology, a library of $5 \alpha, 6 \beta$-dihydroxy steroids has been easily obtained, and further research has provided important data regarding the cytotoxic profile of these compounds [78].

Scheme 22. Trans-diaxial hydroxylation of $\Delta^{5}$-steroids by sequential combination of MMPP epoxidation and $\mathrm{Bi}(\mathrm{OTf})_{3} \cdot \mathrm{xH}_{2} \mathrm{O}$-catalyzed ring opening of epoxides.

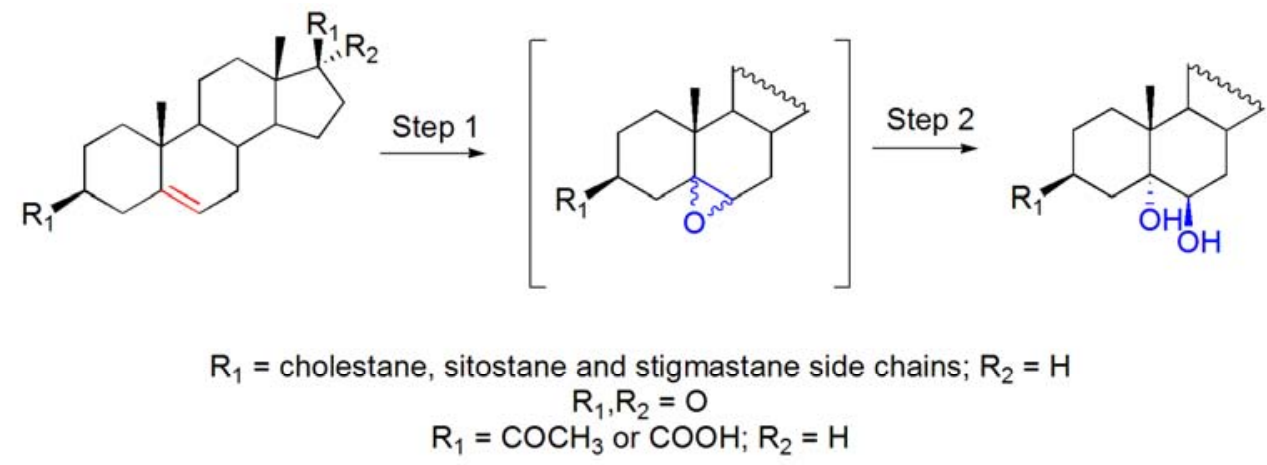

Step 1: MMPP (1.5 eq.), acetone, reflux, $30 \mathrm{~min}$

Step 2: Cooling and then addition of $\mathrm{Bi}(\mathrm{OTf})_{3} \cdot \mathrm{xH}_{2} \mathrm{O}(1.0 \mathrm{eq})$ to the reaction mixture,

or

Cooling, then filtration and later addition of $\mathrm{Bi}(\mathrm{OTf})_{3} \cdot \mathrm{xH}_{2} \mathrm{O}(0.1 \mathrm{eq})$ to the reaction mixture

In this work, some considerations were done regarding the true catalytic species in the ring-opening step. Although the authors demonstrated the importance of Brønsted acid species, either derived from $\mathrm{Bi}(\mathrm{OTf})_{3} \cdot \mathrm{xH}_{2} \mathrm{O}$ or from the oxidant, it has been suggested that $\mathrm{Bi}(\mathrm{OTf})_{3} \cdot \mathrm{xH}_{2} \mathrm{O}$ also participates as Lewis acid in the catalytic cycle, since reactivity has been found, even when the reaction is performed in the presence of stoichiometric amounts of 2,6-DTPB [77].

\section{Rearrangement Reactions}

\subsection{Ferrier rearrangement}

The Ferrier rearrangement is a well known methodology for the preparation of alkyl and aryl 2,3unsaturated- $O$-glycosides by reaction of glycals with alcohols catalyzed by Lewis acids. 
Scheme 23. Bismuth(III) salt-catalyzed Ferrier rearrangement.

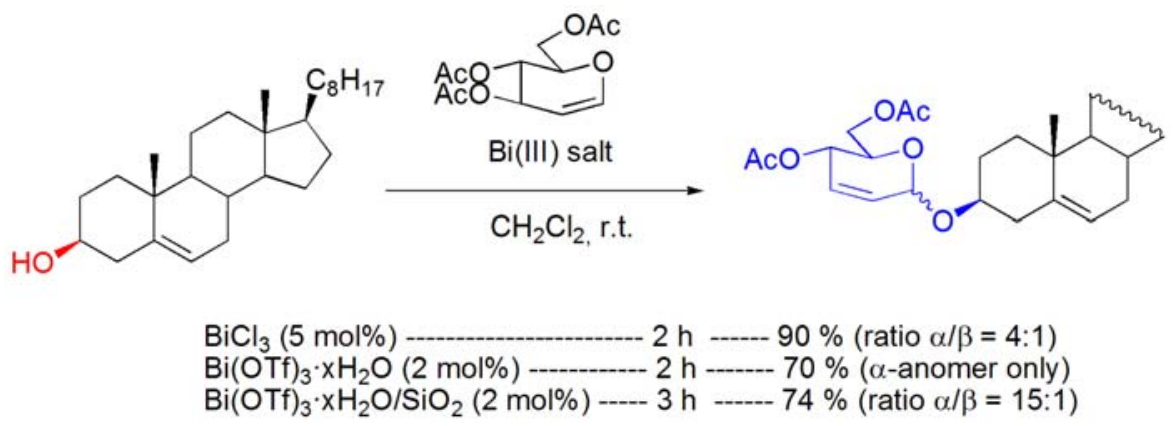

The reaction of cholesterol with 3,4,5-tri-O-acetyl-D-glucal in the presence of $\mathrm{BiCl}_{3}$ or $\mathrm{Bi}(\mathrm{OTf})_{3} \cdot \mathrm{xH}_{2} \mathrm{O}$ afforded the corresponding 2,3-unsaturated- $O$-glycoside, in good yield $[79,80]$. The use of $\mathrm{Bi}(\mathrm{OTf})_{3} \cdot \mathrm{xH}_{2} \mathrm{O}$ or $\mathrm{Bi}(\mathrm{OTf})_{3} \cdot \mathrm{xH}_{2} \mathrm{O} / \mathrm{SiO}_{2}$, proved to be more stereoselective, affording the $\alpha$ anomer almost exclusively (Scheme 23) [80].

\subsection{Epoxyolefin cyclizations}

Epoxyolefin cyclizations are an important area of research since the discovery that these reactions are involved in biosynthetic pathways of terpenes. The cyclization of geraniolene oxide has been investigated in the presence of several metal triflates, including $\mathrm{Bi}(\mathrm{OTf})_{3} \cdot \mathrm{xH}_{2} \mathrm{O}$. The reaction product ratio was found to be mainly influenced by the choice of the solvent and substrate concentration rather than by the choice of the metal triflate. Cyclization products were preferentially formed in $\mathrm{CH}_{2} \mathrm{Cl}_{2}$ and under high dilution conditions whereas acyclic compounds were mostly obtained in ethereal solvents (Scheme 24) [81].

Scheme 24. $\mathrm{Bi}(\mathrm{OTf})_{3} \cdot \mathrm{xH}_{2} \mathrm{O}$-catalyzed cyclization of geraniolene oxide.

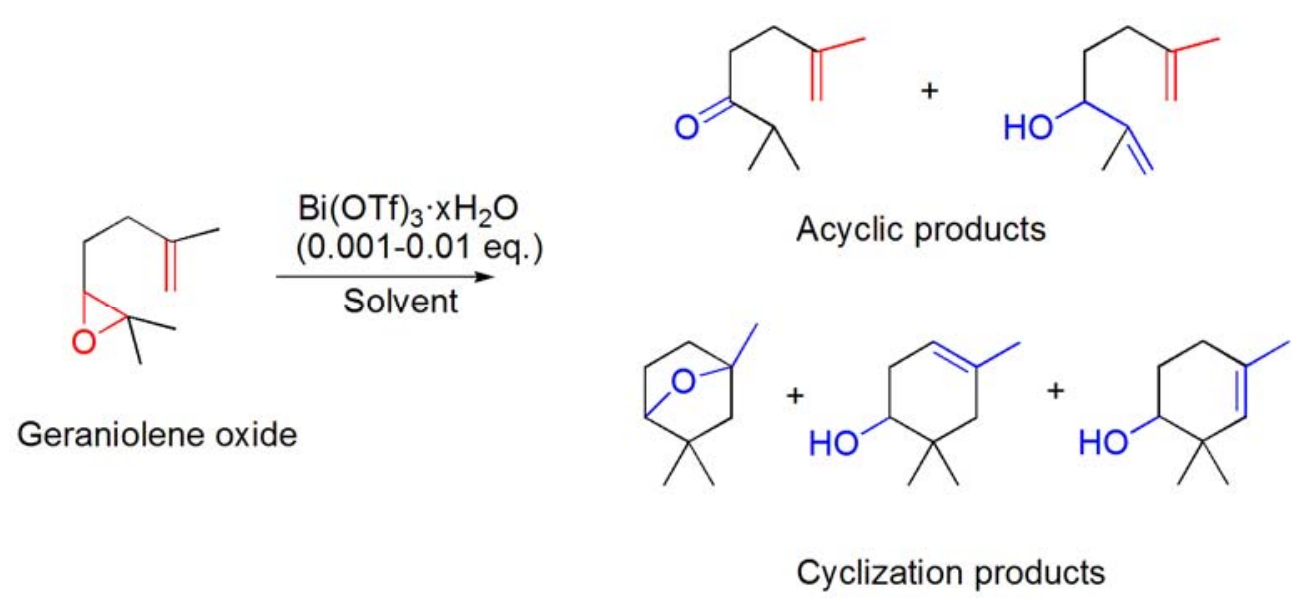

Later, Smith and co-workers evaluated the use of stoichiometric amounts of $\mathrm{BiCl}_{3}$ and $\mathrm{BiOClO}_{4} \cdot \mathrm{xH}_{2} \mathrm{O}$ in the Lewis acid mediated cyclization reactions of 6,7-epoxygeranyl pivalate ester also. Despite the fact that good activity was observed, poor selectivity for the desired bicyclic ether was found [82]. 


\subsection{Westphalen and "Backbone" rearrangements}

Bismuth(III) salts were described as catalysts for the Westphalen and "backbone" rearrangements of $5 \beta, 6 \beta$-epoxysteroids $[83,84]$. The reactions were found to be particularly sensitive to changes on the solvent, temperature, stereochemistry of the starting epoxysteroids and their substituents at $\mathrm{C}-17$. Thus, the $\mathrm{Bi}(\mathrm{OTf})_{3} \cdot \mathrm{xH}_{2} \mathrm{O}$-catalyzed reaction of $5 \beta, 6 \beta$-epoxysteroids from the cholestane, androstane and pregnane series, in 1,4-dioxane, at $80{ }^{\circ} \mathrm{C}$, afforded the corresponding $5 \beta$-methyl- $\Delta^{9(10)}$-19-norsteroids, in moderate yields (Scheme 25, reaction 1). On the other hand, using a solvent with high dielectric constant, such as $\mathrm{CH}_{3} \mathrm{NO}_{2}$, the rearrangement is extended to rings $\mathrm{C}$ and $\mathrm{D}$ of the steroid core and the $5 \beta, 14 \beta$-dimethyl- $\Delta^{13(17)}-18,19$-dinorsteroids from the cholestane and pregnane series were isolated in good yields (Scheme 25, reaction 2) [83,84].

Scheme 25. $\mathrm{Bi}(\mathrm{OTf})_{3} \cdot \mathrm{xH}_{2} \mathrm{O}$-catalyzed Westphalen and "backbone" rearrangements of $5 \beta, 6 \beta$-epoxysteroids.

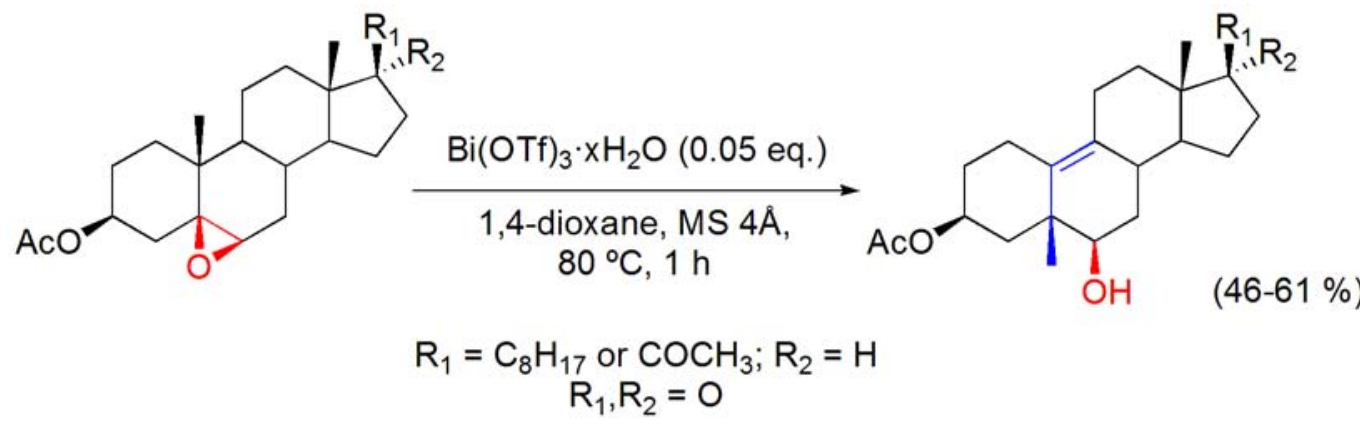

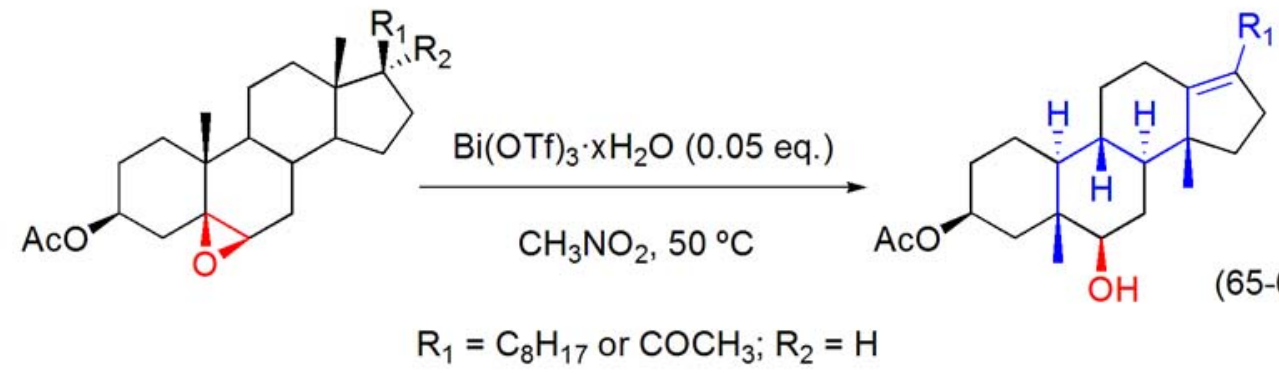

$65-68 \%)$

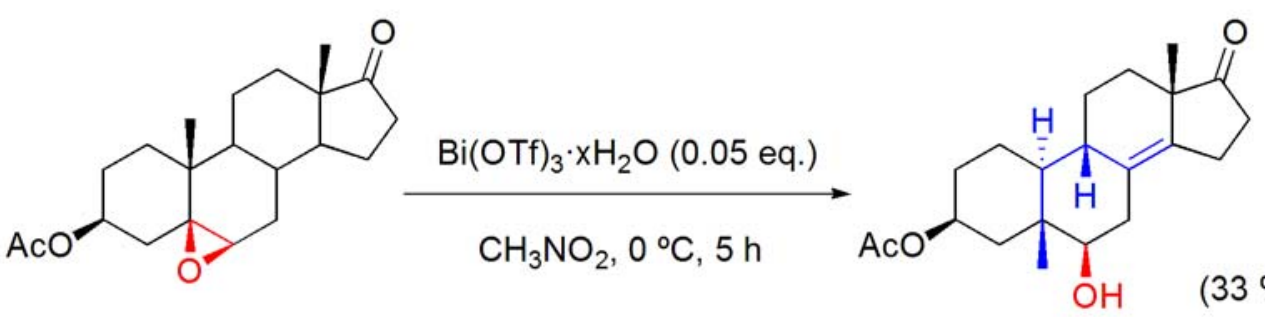

$$
\text { ratio } 5 \beta-\mathrm{Me}-\Delta^{9(10)} / 5 \beta-\mathrm{Me}-\Delta^{8(14)}=29: 71
$$

With the androstane derivative, due to the lack of a $17 \alpha-\mathrm{H}$, a full "backbone" rearrangement was not expected and, in addition to the $5 \beta$-methyl- $\Delta^{9(10)}$-norsteroid derivative, the $5 \beta$-methyl- $\Delta^{8(14)}$-norsteroid was also formed, in $\mathrm{Bi}(\mathrm{OTf})_{3} \cdot \mathrm{xH}_{2} \mathrm{O} / \mathrm{CH}_{3} \mathrm{NO}_{2}$, and isolated in $33 \%$ yield (Scheme 25, reaction 3) [83]. 
An interesting feature of the "backbone" rearranged compounds is their abnormal A/B ring trans-fused $(5 \beta, 10 \alpha)$ steroid structure that was confirmed by X-ray crystallography $[83,84]$. These rearrangements were found to occur specifically with $5 \beta, 6 \beta$-epoxides, and not with their corresponding $5 \alpha, 6 \alpha$ diastereomers. Data obtained from X-ray crystallography and quantum chemical calculation on the equilibrium geometry of the free molecule $[84,85]$ revealed that important steric factors, such as the change in the torsion angle of the steroid nucleus, may contribute to explain the difference in reactivity observed between $5 \beta, 6 \beta$ - and $5 \alpha, 6 \alpha$-epoxysteroids, which do not react under the same reaction conditions, although similar electronic effects are present in these diasteriomeric epoxides. Thus the $5 \beta, 6 \beta$-stereochemistry is essential for the development of 1,3-syn-diaxial interactions with the angular $10 \beta$-methyl group, that are relieved during the rearrangement. In another related study, it has been shown that the "backbone" rearrangement of the $5 \beta, 6 \beta$-epoxide group occurs preferencially to the Wagner-Meerwein rearrangement of the 16 $\alpha, 17 \alpha$-epoxy-20-oxo moiety (Scheme 26) [86].

Scheme 26. $\mathrm{Bi}(\mathrm{OTf})_{3} \cdot \mathrm{xH}_{2} \mathrm{O}$-catalyzed "backbone" rearrangement of $5 \beta, 6 \beta ; 16 \alpha, 17 \alpha-$ diepoxy-20-oxopregnan-3 $\beta$-yl acetate.

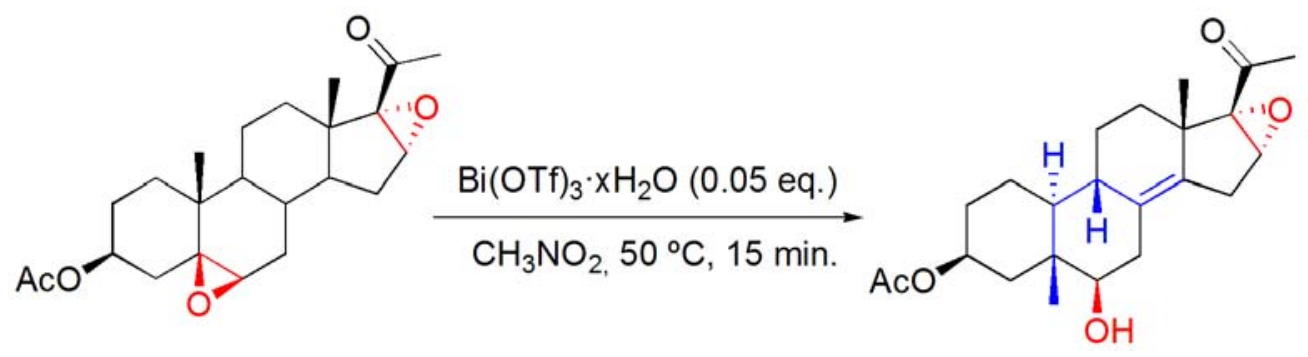

\subsection{Wagner-Meerwein rearrangements}

The application of Westphalen and "backbone" rearrangement reaction conditions [83] to $16 \alpha, 17 \alpha-$ epoxy-20-oxosteroids has also been studied [86]. At room temperature, with 0.05 eq. of catalyst, low conversion of $16 \alpha, 17 \alpha$-epoxy-20-oxopregn-5-en-3 $\beta$-yl acetate was observed. However, on increasing the temperature to $50{ }^{\circ} \mathrm{C}, 16 \alpha$ - and $16 \beta$-hydroxy-17 $\beta$-methyl- $\Delta^{13}-18$-nor pregnane derivatives were formed in near similar amounts from 16 $\alpha, 17 \alpha$-epoxy-20-oxosteroids (Scheme 27) [86].

Several experiments, using HOTf or $\mathrm{La}(\mathrm{OTf})_{3}$ as catalysts instead of $\mathrm{Bi}(\mathrm{OTf})_{3} \cdot \mathrm{xH}_{2} \mathrm{O}$ or with $\mathrm{Bi}(\mathrm{OTf})_{3} \cdot \mathrm{xH}_{2} \mathrm{O}$ in presence of proton scavengers (2,6-DTPB and $\mathrm{BiPh}_{3}$ ), demonstrated that this rearrangement is mediated by Brønsted acid species generated in situ from the catalyst $\mathrm{Bi}(\mathrm{OTf})_{3} \cdot \mathrm{xH}_{2} \mathrm{O}$. It was also observed that the $16 \alpha$-hydroxy-17 $\beta$-methyl- $\Delta^{13}$-18-nor pregnane derivative undergoes epimerization under these reaction conditions.

Thus, it was suggested that an in situ generated Brønsted acid species from $\mathrm{Bi}(\mathrm{OTf})_{3} \cdot \mathrm{xH}_{2} \mathrm{O}$ catalyzes the ring opening of the $16 \alpha, 17 \alpha$-epoxide, creating a tertiary carbocation at $\mathrm{C} 17$ followed by stereoselective 1,2-migration of the $\mathrm{C} 18$-methyl group to the $17 \beta$-position. Due to the $18-\mathrm{CH}_{3} \rightarrow 17$ $\mathrm{CH}_{3}$ shift, a carbocation centered at $\mathrm{C} 13$ is formed, and further $14 \alpha-\mathrm{H}$ elimination originates the $\Delta^{13}$ double bond. $16 \beta$-Epimers can be formed due to an acid-catalyzed reverse-aldol equilibrium involving the 16-hydroxy-20-keto function of the rearranged steroid, under the reaction conditions employed, which is responsible for the epimerization at C16. (Scheme 28) [86]. 
Scheme 27. $\mathrm{Bi}(\mathrm{OTf})_{3} \cdot \mathrm{xH}_{2} \mathrm{O}$-catalyzed Wagner-Meerwein rearrangement of $16 \alpha, 17 \alpha-$ epoxy-20-oxosteroids.

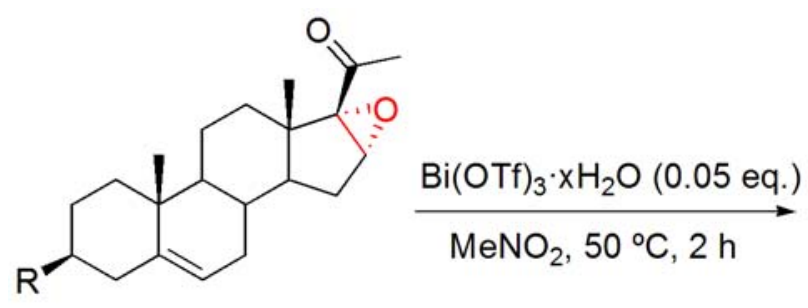

$\mathrm{R}=\mathrm{OAc}$ or $\mathrm{OH}$<smiles>CC(=O)[C@]1(C)C2=C(C[C@H]2O)C[C@H]1O</smiles>

crude yield $95-98 \%$ ratio $16 \alpha / 16 \beta$-epimers $\sim 1: 1$

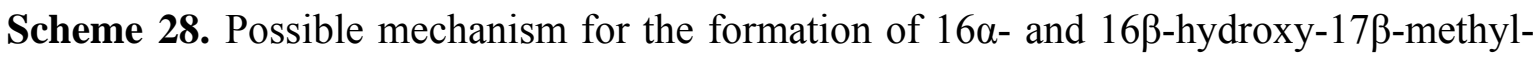
$\Delta^{13}-18$-norsteroids.

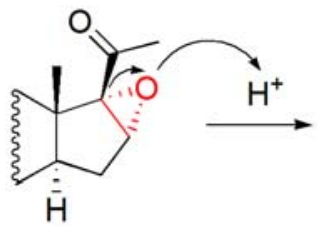

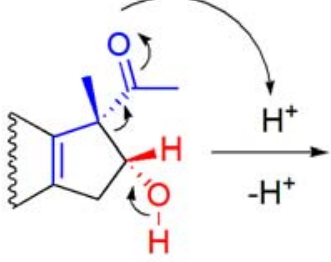

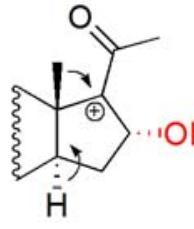<smiles>C[IH+]</smiles><smiles>O[C@H]1C[C@@H](O)C2=C1[C@H]1CC[C@H]2C1</smiles>

$16 \alpha$-hydroxy-17 $\beta$-methyl$\Delta^{13}$-18-nor product<smiles>CC1=C(C)C(O)=C(C)C2=C(CC2)CC(=O)C1</smiles><smiles>C[PH+][C@@H]1CC2=C([C@H](O)C2)[C@@]1(C)C(C)=O</smiles>

$16 \alpha-$ and $16 \beta$ hydroxy epimers

Scheme 29. $\mathrm{Bi}(\mathrm{OTf})_{3} \cdot \mathrm{xH}_{2} \mathrm{O}$-catalyzed Wagner-Meerwein rearrangement in the presence of acylation reagents.

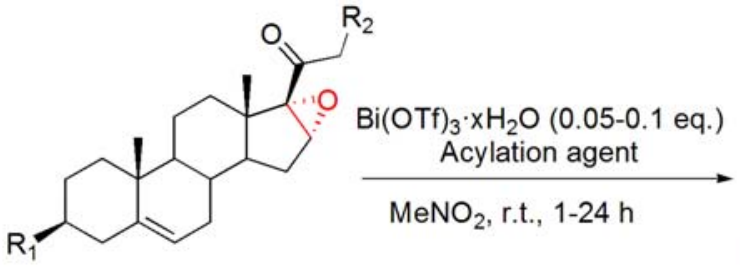

$\mathrm{R}_{1}=\mathrm{OH}$ or $\mathrm{OAC}$

$\mathrm{R}_{2}=\mathrm{H}$ or OAC $\mathrm{R}_{3}=\mathrm{Ac}, \mathrm{CH}_{3}\left(\mathrm{CH}_{2}\right)_{2} \mathrm{CO}$

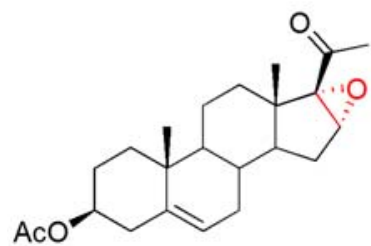

$\mathrm{Bi}(\mathrm{OTf})_{3} \cdot \mathrm{xH}_{2} \mathrm{O}$ (0.05 eq.) $\mathrm{HCO}_{2} \mathrm{Et}$, reflux, $24 \mathrm{~h}$<smiles>[R]CC(=O)[C@@]1(C)C2=C(C[C@H]1O[R3])[C@@H]1CC=C3CC([R])CC[C@]3(C)[C@H]1CC2</smiles> 
In order to increase the stereoselectivity of the rearrangement, the reactions were studied in the presence of $\mathrm{Ac}_{2} \mathrm{O}$. In fact, it was observed that $16 \alpha$-acetoxy rearranged derivatives were selectively prepared. To enlarge the scope of this $\mathrm{Bi}(\mathrm{OTf})_{3} \cdot \mathrm{xH}_{2} \mathrm{O}$-catalyzed rearrangement, other acylation agents were used, and several $17 \beta$-methyl- $\Delta^{13}$-18-norsteroids bearing different acyl groups at positions $\mathrm{C} 3$, C16 and C21 were selectively prepared (Scheme 29) [86].

Wagner-Meerwein type rearrangements have also been widely reported in terpene chemistry [87]. One of such well-known transformations involves the acid catalyzed ring E rearrangement of betulin and important related triterpene derivatives, to $18 \alpha$-oleanane compounds bearing a 19ק,28-epoxide or 28,19ß-lactone ring, and is commonly referred to "betulin-allobetulin rearrangement". Following the previous knowledge that bismuth(III) salts are able to catalyze Wagner-Meerwein type rearrangements, their advantageous use as catalysts for the Wagner-Meerwein rearrangement of lupanes has recently been reported [57]. Thus, using $\mathrm{CH}_{2} \mathrm{Cl}_{2}$ as solvent and with $\mathrm{Bi}(\mathrm{OTf})_{3} \times \mathrm{xH}_{2} \mathrm{O}$ catalysis ( 0.05 to 0.5 eq.), several lupane derivatives undergo a Wagner-Meerwein rearrangement with expansion of ring $\mathrm{E}$ and formation of an additional $O$-containing ring. By using this process [with 0.05 eq. of $\mathrm{Bi}(\mathrm{OTf})_{3} \cdot \mathrm{xH}_{2} \mathrm{O}$ ], several interesting $18 \alpha$-oleananes could be efficiently obtained from lupanes by a single Wagner-Meerwein rearrangement (Scheme 30) [57,88].

Some mechanistic studies were performed, in a similar fashion to what has been done during the

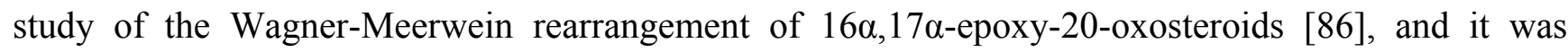
demonstrated that these reactions are catalyzed by Brønsted acid species generated in situ from the hydrolysis of $\mathrm{Bi}(\mathrm{OTf})_{3} \cdot \mathrm{xH}_{2} \mathrm{O}$. Therefore, the reaction mechanism can be postulated as follow. Under this reaction conditions, $\mathrm{Bi}(\mathrm{OTf})_{3} \cdot \mathrm{xH}_{2} \mathrm{O}$ undergo a reversible hydrolysis leading to the formation of bismuth-containing cationic species [17] and thus the formation of an in situ Brønsted acid species. The hydrolysis of $\mathrm{Bi}(\mathrm{OTf})_{3} \cdot \mathrm{xH}_{2} \mathrm{O}$ has been shown to lead to the quantitative formation of triflic acid, in water [89], however experimental data under this reaction conditions do not allowed to conclude it, unquivocally. Anyway, the Brønsted acid species formed in situ catalysis the formation of successive carbocations that are eventually trapped by intramolecular nuclophylic attach by the C28-hydroxyl group (Scheme 31) [57].

Scheme 30. $\mathrm{Bi}(\mathrm{OTf})_{3} \cdot \mathrm{xH}_{2} \mathrm{O}$-catalyzed Wagner-Meerwein rearrangement of betulin and betulinic acid derivatives.
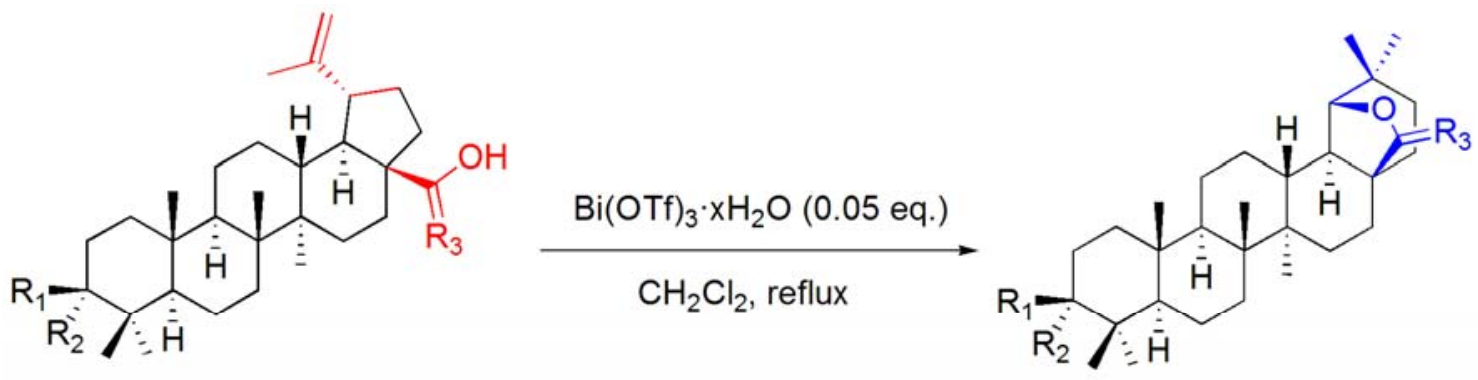

$$
\begin{aligned}
& \begin{array}{c}
\mathrm{R}_{1}=\underset{\mathrm{OH}}{\mathrm{O}}, \mathrm{Ac} \text { and } \mathrm{R}_{2}=\mathrm{H} \\
\mathrm{R}_{1}, \mathrm{R}_{2}=\mathrm{O}
\end{array} \\
& \mathrm{R}_{3}=\mathrm{H}_{2} \text { : betulin derivatives } \\
& \mathrm{R}_{3}=\mathrm{O} \text { : betulinic acid derivatives }
\end{aligned}
$$


Under more vigorous conditions $\left(0.2-0.5\right.$ eq. of $\left.\mathrm{Bi}(\mathrm{OTf})_{3} \cdot \mathrm{xH}_{2} \mathrm{O}\right)$, the dehydration of the $3 \beta$-hydroxyl group occurred and the resulting compounds underwent a double Wagner-Meerwein rearrangement, originating A-neo-18 $\alpha$-oleanene compounds in high yields (Scheme 32). This process was also applied the sesquiterpene (-)-caryophyllene oxide, to afford clov-2-en-9 $\alpha$-ol by a "caryophyllene-clovane rearrangement" (Scheme 33).

Scheme 31. Possible mechanism for the $\mathrm{Bi}(\mathrm{OTf})_{3} \cdot \mathrm{xH}_{2} \mathrm{O}$-catalyzed Wagner-Meerwein rearrangement of betulin to allobetulin.
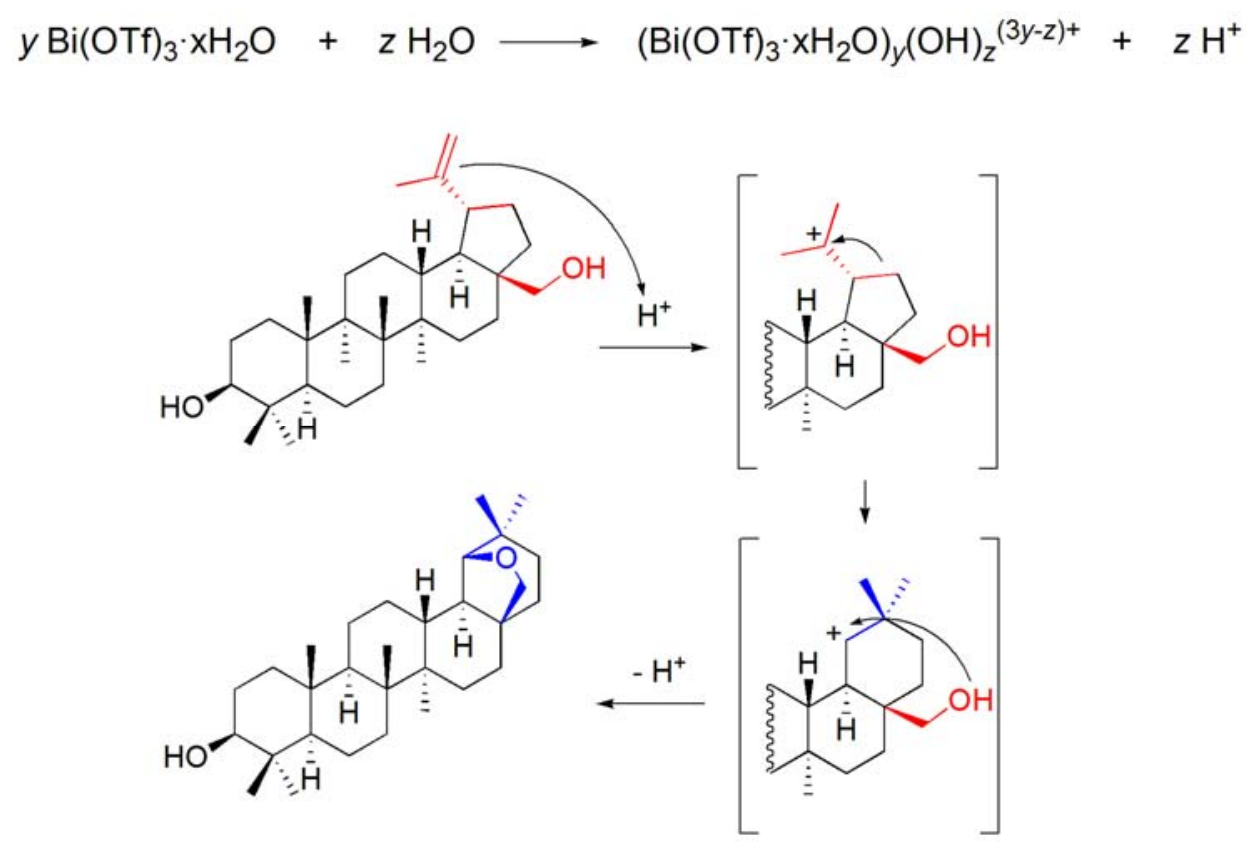

Scheme 32. $\mathrm{Bi}(\mathrm{OTf})_{3} \cdot \mathrm{xH}_{2} \mathrm{O}$-promoted dehydration and double Wagner-Meerwein rearrangement of betulin $\left(\mathrm{R}_{1}=\mathrm{H}_{2}\right)$ and betulinic acid $\left(\mathrm{R}_{1}=\mathrm{O}\right)$.

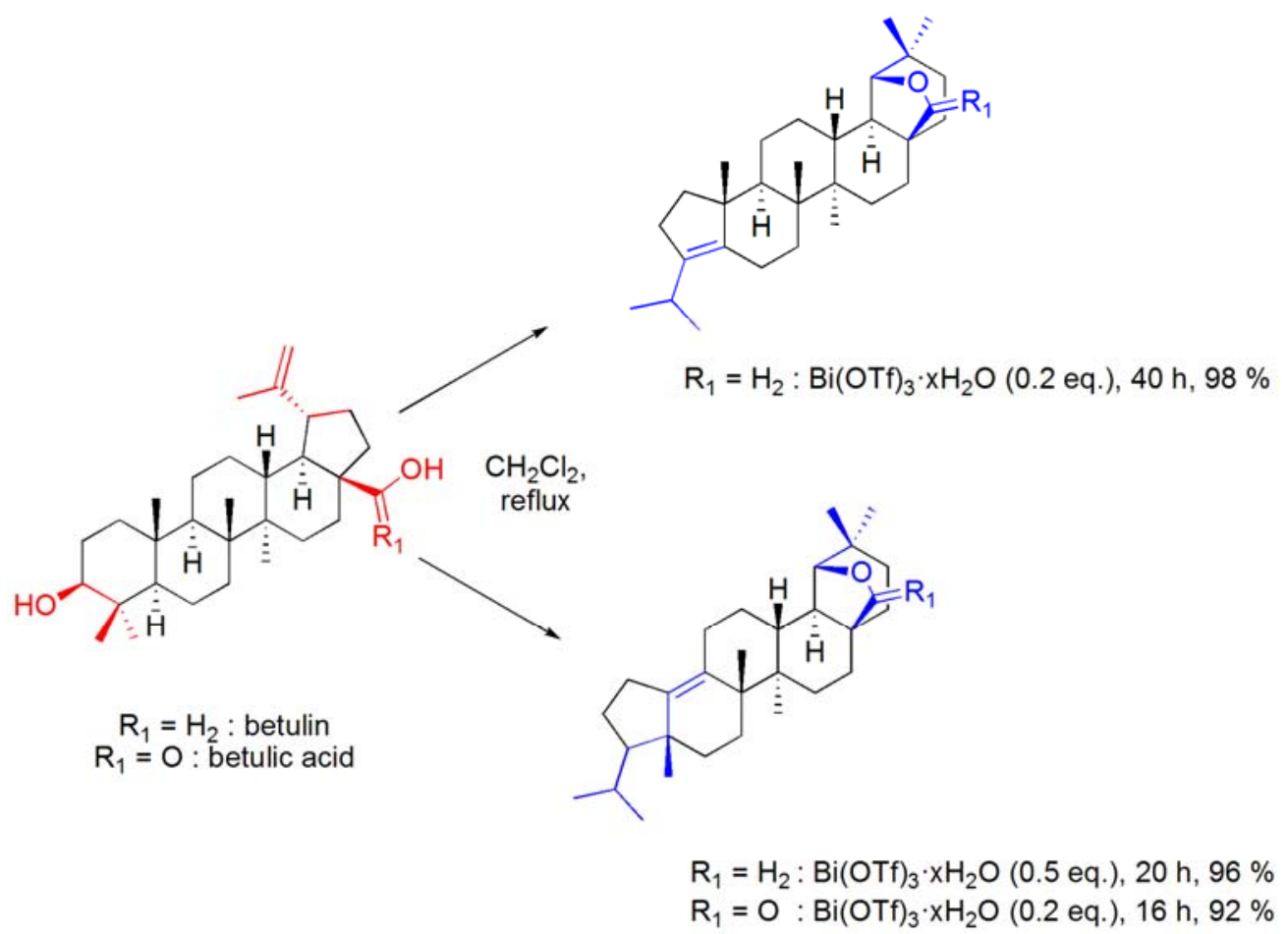


Scheme 33. $\mathrm{Bi}(\mathrm{OTf})_{3} \cdot \mathrm{xH}_{2} \mathrm{O}$-catalyzed rearrangement of $(-)$-caryophyllene oxide.
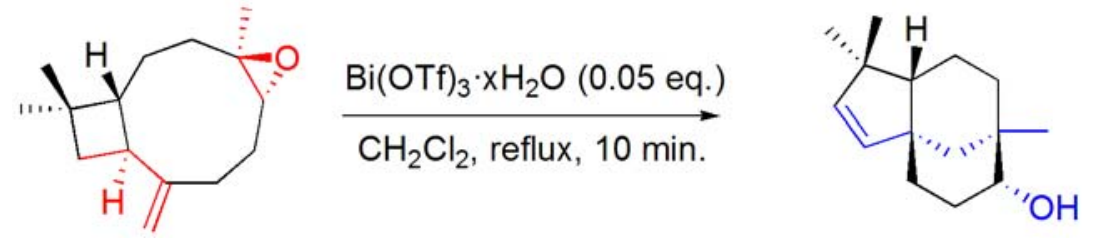

\subsection{Oxidative rearrangement of tertiary allylic alcohols}

Recently, a new method for the oxidative rearrangement of tertiary allylic alcohols to the corresponding transposed carbonyl derivatives using TEMPO in combination with $\mathrm{PhIO}$ and $\mathrm{Bi}(\mathrm{OTf})_{3} \cdot \mathrm{xH}_{2} \mathrm{O}$ was described. However, when applied to the terpenic derivative 2-methylcarveol, this procedure only led to $19 \%$ yield of 3-methylcarvone (Scheme 34) [90,91].

Scheme 34. $\mathrm{Bi}(\mathrm{OTf})_{3} \cdot \mathrm{xH}_{2} \mathrm{O}$-catalyzed oxidative rearrangement of 2-methylcarveol.
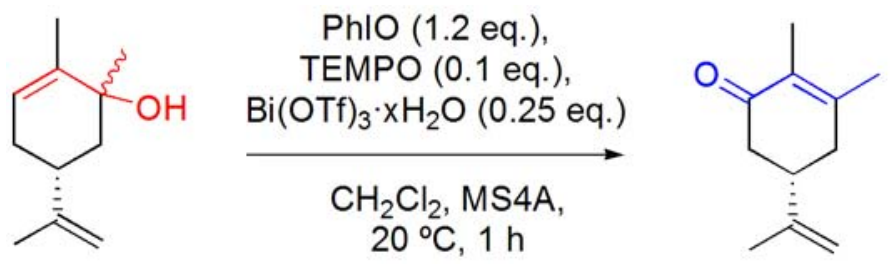

\section{Miscellaneous Reactions}

\subsection{Diels-Alder cycloaddition}

$(+)$-Menthol was used as an inexpensive chiral auxiliary in the course of the development of a largescale production process for the preparation of the enantiomerically pure $(2 R, 3 R)$-bicyclo[2.2.1] hept-5ene-2,3-dicarboxylic acid, an intermediate in the synthesis of the adenosine A1 antagonist BG9719 (CVT-124). In this context, he asymmetric Diels-Alder reaction of (+)-dimenthyl fumarate and cyclopentadiene has been extensively investigated in order to determine which conditions lead to the best yield and diastereomeric excess. Among the Lewis acids tested, $\mathrm{BiCl}_{3}$ promoted reaction rendered $100 \%$ conversion, but poor diastereomeric excess (Scheme 35) [92].

Scheme 35. $\mathrm{BiCl}_{3}$-promoted Diels-Alder reaction of (+)-dimenthyl fumarate and cyclopentadiene.
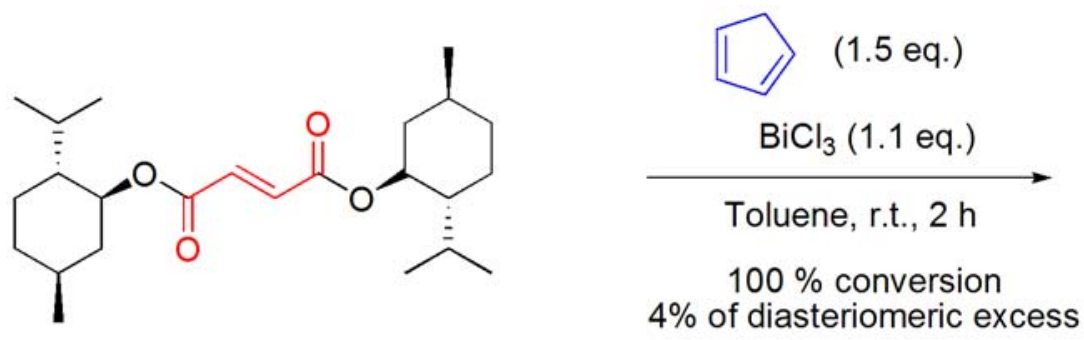

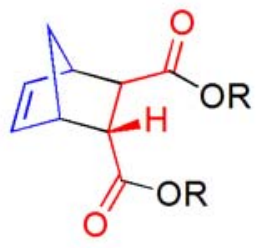

$\mathrm{R}=(+)$-menthyl 


\subsection{Ene reaction}

The $\mathrm{BiCl}_{3}$-catalyzed reaction of (-)- $\beta$-pinene with an equimolar amount of chloral in $\mathrm{CH}_{2} \mathrm{Cl}_{2} / \mathrm{Et}_{2} \mathrm{O}$ gave the corresponding $\mathrm{H}$-ene adduct, in 49\% yield [ratio $(11 R) /(11 S)$-diastereomers $=64: 36$ ] (Scheme 36) $[93]$.

Scheme 36. $\mathrm{BiCl}_{3}$-catalyzed ene reaction of (-)- $\beta$-pinene with chloral.<smiles>C=C1CC2CC1CC2(C)C</smiles><smiles>O=CC(Cl)(Cl)Cl</smiles>

(-)- $\beta$-Pinene<smiles>CCOCCO[Mg]</smiles>

$\mathrm{CH}_{2} \mathrm{Cl}_{2} / \mathrm{Et}_{2} \mathrm{O}(9: 1 \mathrm{v} / \mathrm{v})$, r.t.<smiles>O[C@H](CC1=CCC2CC1C2)C(Cl)(Cl)Cl</smiles>

$$
\text { ratio }(11 R) /(11 S) \text {-diastereomers }=64: 36
$$

A well known example of an intramolecular ene reaction is the cyclization of citronellal to (-)isopulegol, an important intermediate in the industrial production of (-)-menthol (Takasago process). This reaction has been reported to be catalyzed by $\mathrm{BiCl}_{3}(2-5 \mathrm{~mol} \%)$ [93] and $\mathrm{Bi}(\mathrm{OTf})_{3} \cdot \mathrm{xH}_{2} \mathrm{O}$ $(0.1 \mathrm{~mol} \%)$ (Scheme 37) [94]. Along with the desired product, neoisopulegol was also formed in low amounts $(<30 \%)$ in both processes.

Scheme 37. $\mathrm{Bi}(\mathrm{OTf})_{3} \cdot \mathrm{xH}_{2} \mathrm{O}$-catalyzed cyclization of citronellal.<smiles>CC(C)=CCCC(C)CC=O</smiles>

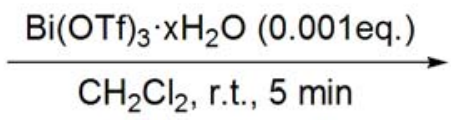<smiles></smiles>

$78 \%$<smiles>CC(=O)OC1CC[C@@H](C)CC1O</smiles>

$22 \%$

\subsection{Aromatic nitration reactions using $\mathrm{Bi}\left(\mathrm{NO}_{3}\right)_{3} \cdot 5 \mathrm{H}_{2} \mathrm{O}$}

Montmorillonite impregnated with bismuth nitrate was found to be an efficient reagent for the nitration of estrone affording the 2-nitro and 4-nitro derivatives as a 1:1 mixture, in 94\% yield [95,96].

Scheme 38. Nitration of estrone using $\mathrm{Bi}\left(\mathrm{NO}_{3}\right)_{3} \cdot 5 \mathrm{H}_{2} \mathrm{O}$.<smiles>C[C@]12CCC3c4ccc(O)cc4CCC3C1CCC2=O</smiles>

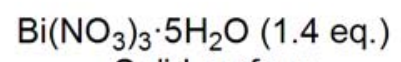<smiles>O=[N+]([O-])c1cc2c(cc1O)CC2</smiles><smiles>O=[N+]([O-])c1cc2c(c([N+](=O)[O-])c1O)CC2</smiles>

ratio 2-nitro/2,4-dinitro $=5: 1$ 
More recently, the same group reported further developments of the initial methodology using various metal nitrates, including $\mathrm{Bi}\left(\mathrm{NO}_{3}\right)_{3} \cdot 5 \mathrm{H}_{2} \mathrm{O}$, and screened several solid supports and reaction conditions. The best results with $\mathrm{Bi}\left(\mathrm{NO}_{3}\right)_{3} \cdot 5 \mathrm{H}_{2} \mathrm{O}$ were accomplished using Florisil or molecular sieves, in refluxing benzene, in a Dean Stark apparatus, or alumina, under dry conditions. With these reaction conditions, a 5:1 ratio of the 2-nitro and the 2,4-dinitro derivatives was obtained (Scheme 38) [97].

\subsection{Lactonization of $\Delta^{12}$-oleananes}

During the study of the $\mathrm{Bi}(\mathrm{OTf})_{3} \cdot \mathrm{xH}_{2} \mathrm{O}$-catalyzed Wagner-Meerwein rearrangement of terpenes, it was found that this reagent is able to promote the 28,13 $\beta$-lactonization of oleanonic acid (Scheme 39) [57]. Interestingly, under bismuth catalysis, a carbocation is formed not only at C13 but also at C18, as shown by the observed inversion of the configuration of the $\mathrm{C} 18$-stereocenter, which has been confirmed by X-ray data [98].

Scheme 39. $\mathrm{Bi}(\mathrm{OTf})_{3} \cdot \mathrm{xH}_{2} \mathrm{O}$-promoted lactonization of oleanonic acid.
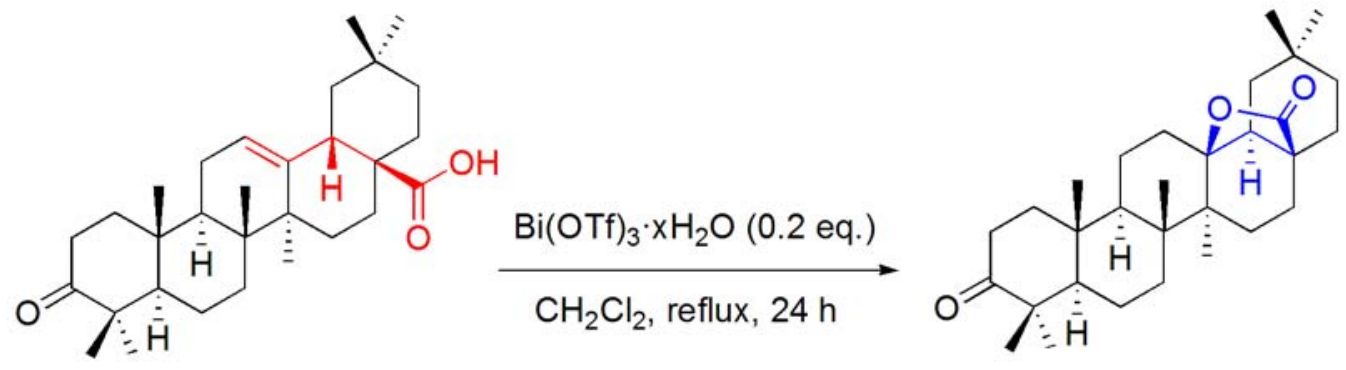

(95\%)

\subsection{Cleavage of the C17-side chain of corticosteroids}

A quite recent report showed that $\mathrm{Bi}(\mathrm{OTf})_{3} \cdot \mathrm{xH}_{2} \mathrm{O}$ is an efficient catalyst for the conversion of corticosteroids into highly functionalized 17-ketosteroids, by cleavage of the C17-dihydroxyacetone side chain [99]. This reaction was typically performed using large amounts of oxidative or basic reactants [100-102]. The use of other bismuth(III) salts and other solvents has been tested, however the best results have been obtained with 0.05 eq. of $\mathrm{Bi}(\mathrm{OTf})_{3} \cdot \mathrm{xH}_{2} \mathrm{O}$, in 1,4-dioxane, at $80{ }^{\circ} \mathrm{C}$. Under this reaction conditions, non-steroidal by-products have been observed. Their presence probably arises from the acid-catalyzed polymerization of the $\alpha$-hydroxy ketone moiety derived from the cleavage of the corticosteroid side chain. Thus, purification by flash chromatography was needed to obtain pure 17-ketosteroids. Using this method several highly functionalized 17-ketosteroids have been prepared (Scheme 40).

The process proved to be very chemoselective, since functionalities of the starting corticosteroids,

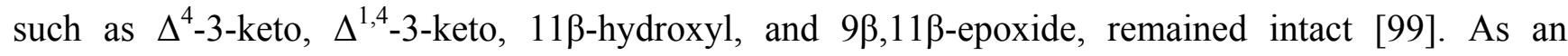
important drug class in the treatment of a variety of clinical situations [103], corticosteroids are readily available compounds. In fact, their industrial production reaches several tonnes per year [104], making this new process an useful source of substrates to obtain other steroids bearing a variety of chemical functions in rings $\mathrm{A}, \mathrm{B}, \mathrm{C}$ and $\mathrm{D}$. 
Scheme 40. $\mathrm{Bi}(\mathrm{OTf})_{3} \cdot \mathrm{xH}_{2} \mathrm{O}$-catalyzed cleavage of the $\mathrm{C} 17$-dihydroxyacetone side chain of corticosteroids.

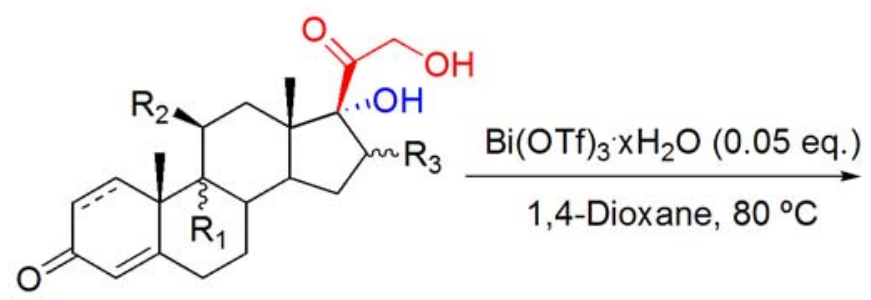<smiles>[R]C1C[C@H]2[C@@H]3CCC4=CC(=O)C=C[C@]4(C)[C@@]3([R])C[C@H]([R3])[C@@]2(C)C1=O</smiles>

$$
\begin{gathered}
\mathrm{R}_{1}=\alpha-\mathrm{H}, \alpha-\mathrm{Cl} \text { or } \alpha-\mathrm{F} ; \\
\mathrm{R}_{2}=\mathrm{OH}, \text { or } \mathrm{R}_{1}, \mathrm{R}_{2}=\beta \text {-epoxide } \\
\mathrm{R}_{3}=\mathrm{H}, \alpha-\mathrm{CH}_{3} \text { or } \beta-\mathrm{CH}_{3}
\end{gathered}
$$

It is interesting to note that when the reaction was performed using HOTf as catalyst, only $11 \%$ of

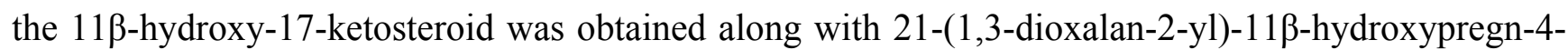
ene-3,20-dione, in 45\% yield, as the major reaction product (Scheme 41, reaction 1). Moreover, using the $\mathrm{Bi}(\mathrm{OTf})_{3} \cdot \mathrm{xH}_{2} \mathrm{O} / 2,6$-DTBP system, the desired product was obtained in good yield, after a longer reaction time (Scheme 41, reaction 2). Therefore, although Brønsted acid catalysis was observed, it seems the $\mathrm{Bi}(\mathrm{OTf})_{3} \cdot \mathrm{xH}_{2} \mathrm{O}$-catalyzed cleavage of the $\mathrm{C} 17$-dihydroxyacetone side chain of corticosteroids is mediated by Lewis acid catalysis [99]. In the absence of proton scavenger, Brønsted acid-assisted Lewis acid catalysis [25] is observed, as suggested by the higher reaction rate.

Scheme 41. Cleavage of the C17-dihydroxyacetone side chain of corticosteroids under Brønsted acid and Lewis acid catalysis.

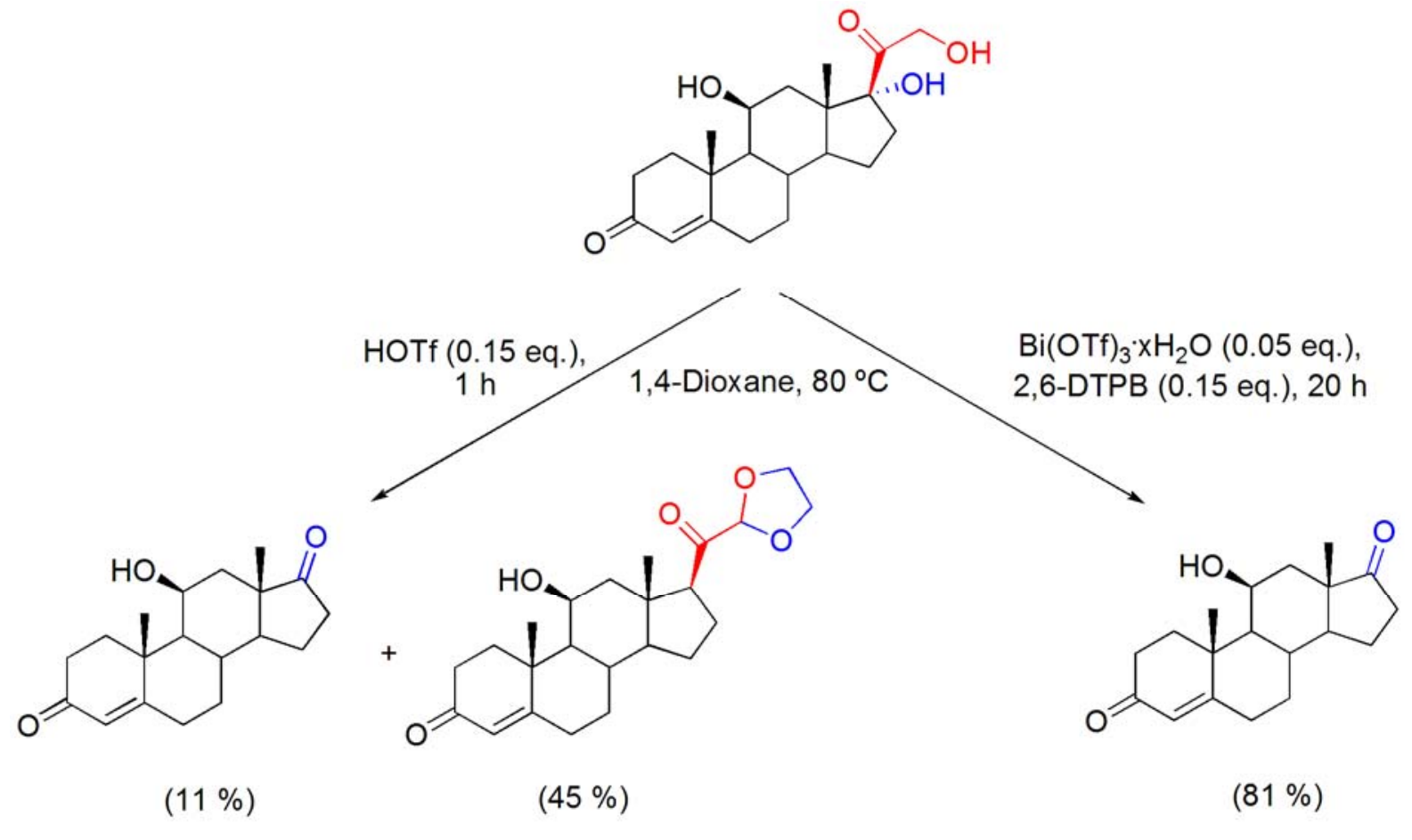

(1) 


\section{Conclusions}

In the past five years, several new bismuth-based processes have been reported in the field of steroid and terpene chemistry, which added new "ecofriendly" tools for the synthesis of valorous molecules.

Efforts have been made to tentatively identify the nature of the true catalytic species. Many literature reports attributed the reactivity to the Lewis acid nature of the bismuth(III) salts, however others explain the observed catalytic reaction as result of a Brønsted acid species formed in situ from bismuth(III) salt. In addition, Brønsted acid-assisted Lewis acid catalysis and Lewis acid-assisted Brønsted acid catalysis have also been found in selected transformations, involving bismuth(III) salts. This chemical behavior is responsible for many interesting reactivities of bismuth(III) salts towards steroids and terpenes. In fact, these catalysts were able to promote transformations that only have been earlier performed under extremely hard reaction conditions, such as strong mineral acids or powerful oxidant or basic reactants.

Besides the great advances that have been obtained so far, more research in the development of new bismuth-based processes using steroid and terpenes of pharmaceutical interest is required. Moreover, incorporation of some of these procedures, in the design of large scale synthetic approaches for the preparation of selected steroid and terpenes, in a near future, will be expected.

\section{Acknowledgements}

J. A. R. Salvador thanks to University of Coimbra for financial support. Samuel M. Silvestre thanks to FCT for a post-doctoral grant (SFRH/BPD/41612/2007).

\section{References and Notes}

1. Hanson, J.R. Steroids: Partial synthesis in medicinal chemistry. Nat. Prod. Rep. 2010, 27, 887-899.

2. Gershenzon, J.; Dudareva, N. The function of terpene natural product in the natural world. Nat. Chem. Biol. 2007, 3, 408-414.

3. Trost, B.M. Atom economy - A challenge for organic synthesis: Homogeneous catalysis leads the way. Angew. Chem. Int. Ed. 1995, 34, 259-281.

4. Clark, J.H. Catalysis for green chemistry. Pure Appl. Chem. 2001, 73, 103-111.

5. Anastas, P.T.; Kirchhoff, M.M. Origins, current status, and future challenges of green chemistry. Acc. Chem. Res. 2002, 35, 686-694.

6. Horvath, I.T.; Anastas, P.T. Innovations and green chemistry. Chem. Rev. 2007, 107, 2169-2173.

7. Sheldon, R.A. E factors, green chemistry and catalysis: An odyssey. Chem. Commun. 2008, 3352-3365.

8. Postel, M.; Duñach, E. Bismuth derivatives for the oxidation of organic compounds. Coord. Chem. Rev. 1996, 155, 127-144.

9. Marshall, J.A. Organic chemistry of Bi(III) compounds. Chemtracts: Org. Chem. 1997, 1064-1075. 
10. Suzuki, H.; Ikegami, T.; Matano, Y. Bismuth in organic transformations. Synthesis 1997, 249-267.

11. Komatsu, N. Bismuth compounds in organic transformations; In Organobismuth Chemistry; Suzuki, H., Matano, Y., Eds.; Elsevier: Amsterdam, The Netherlands, 2001; pp. 371-440.

12. Vidal, S. Bismuth(III) derivatives: New catalysts. Synlett 2001, 1194-1195.

13. Le Roux, C.; Dubac, J. Bismuth(III) chloride and triflate: Novel catalysts for acylation and sulfonylation reactions. Survey and mechanistic aspects. Synlett 2002, 181-200.

14. Leonard, N.M.; Wieland, L.C.; Mohan, R.S. Applications of bismuth(III) compounds in organic synthesis, Tetrahedron 2002, 58, 8373-8397.

15. Antoniotti, S. Bismuth(III) tris(trifluoromethanesulfonate). Synlett 2003, 1566-1567.

16. Antoniotti, S.; Duñach, E. Recent uses of bismuth derivatives in organic synthesis. C. R. Chim. 2004, 7, 679-688.

17. Gaspard-Iloughmane, H.; Le Roux, C. Bismuth(III) triflate in organic synthesis. Eur. J. Org. Chem. 2004, 2517-2532.

18. Loh, T.-P.; Chua, G.-L. Activation of reactions by Lewis acids derived from Ga, In, Sb and Bi. In Advances in Organic Synthesis; Atta-ur-Rahman, Ed.; Bentham Science Publishers: Oak Park, IL, USA, 2005; Volume 1, pp. 173-214.

19. Mulamoottil, V.A. Bismuth(III) nitrate pentahydrate-A versatile reagent in organic synthesis. Synlett 2005, 2699-2700.

20. Gaspard-Iloughmane, H.; Le Roux, C. Recent advances in the use of bismuth(III) triflate in organic synthesis: an update. Trends Org. Chem. 2006, 11, 65-80.

21. Gaspard-lloughmane, H.; Le Roux, C. Bismuth(III) lewis acids; In Acid Catalysis for Modern Organic Synthesis; Yamamoto, H., Ishihara, K., Eds.; Wiley: New York, NY, USA, 2008; pp. 551-588.

22. Hua, R.M. Recent advances in bismuth-catalyzed organic synthesis. Curr. Org. Synth. 2008, 5, $1-27$.

23. Salvador, J.A.R.; Pinto, R.M.A.; Silvestre, S.M. Recent Advances of Bismuth(III) Salts in Organic Chemistry: Application to the Synthesis of Aliphatics, Alicyclics, Aromatics, Amino Acids and Peptides, Terpenes and Steroids of Pharmaceutical Interest. Mini-Rev. Org. Chem. 2009, 6, 241-274.

24. Salvador, J.A.R.; Pinto, R.M.A.; Silvestre, S.M. Recent Advances of Bismuth(III) Salts in Organic Chemistry: Application to the Synthesis of Heterocycles of Pharmaceutical Interest. Curr. Org. Synth. 2009, 6, 426-470.

25. Yamamoto, H.; Futatsugi, K. "Designer acids": Combined acid catalysis for asymmetric synthesis. Angew. Chem. Int. Ed. 2005, 44, 1924-1942.

26. Holden, B.; Rigby, W. The bismuth-catalysed air-oxidation of acyloins. J. Chem. Soc. 1951, 1924-1925.

27. Rigby, W. A new reagent for the oxidation of acyloins to diketones. J. Chem. Soc. 1951, 793-795.

28. Djerassi, C.; Ringold, H.J.; Rosenkranz, G. Steroidal sapogenins. 15. Experiments in the hecogenin series (Part 3). Conversion to cortisone. J. Am. Chem. Soc. 1951, 73, 5513-5514.

29. Djerassi, C.; Ringold, H.J.; Rosenkranz, G. Steroidal sapogenins. 37. Experiments in the hecogenin series (Part 6). Conversion to cortisone. J. Am. Chem. Soc. 1954, 76, 5533-5536. 
30. Becker, E.J.; Cohen, A. 12-Keto progestational steroids and derivatives thereof. US Patent 3,185,713, 25 May 1965.

31. Kurath, P. Structure and stereochemistry of benzilic acid rearrangement product of $3 \alpha, 17 \beta-$ diacetoxy-11-Hydroxy-5 $\beta$-androst-9(11)-en-12-one. J. Org. Chem. 1967, 32, 3626-3635.

32. Baran, J.S. 2-Hydroxy- $\Delta^{1,4}-3$-keto steroids. J. Am. Chem. Soc. 1958, 80, 1687-1691.

33. Chaudhry, G.R.; Halsall, T.G.; Jones, E.R.H. Chemistry of triterpenes and related compounds. 39. Some derivatives of 4,4-dimethylcholestan-3-one. J. Chem. Soc. 1961, 2725-2732.

34. Marsh, D.A.; Brodie, H.J.; Garrett, W.; Tsaimorris, C.H.; Brodie, A.M.H. Aromatase inhibitors. Synthesis and biological activity of androstenedione derivatives. J. Med. Chem. 1985, 28, 788-795.

35. Agnello, E.J.; Laubach, G.D.; Figdor, S.K.; Pinson, R.; Ordway, H.W.; Bloom, B.M.; Hughes, G.M.K. A stereospecific synthesis of C-21-methylated corticosteroids. J. Org. Chem. 1963, 28, 1531-1539.

36. Kupchan, S.M.; Lavie, D. Schoenocaulon alkaloids. III. The bismuth oxide oxidation of veracevine, cevagenine and cevine. J. Am. Chem. Soc. 1955, 77, 683-686.

37. Reitsema, R.H. The Synthesis of Racemic Piperitenone Oxide and Diosphenolene. J. Am. Chem. Soc. 1957, 79, 4465-4468.

38. Corey, E.J.; Tius, M.A.; Das, J. Total synthesis of (+/-)-aphidicolin. J. Am. Chem. Soc. 1980, 102, $1742-1744$.

39. Lavie, D.; Shvo, Y. Constituents od Ecballium elaterium L.: Proposed structures for elatericin A and elatericin B. Chem. Ind. 1959, 429-430.

40. Lavie, D.; Shvo, Y.; Willner, D.; Enslin, P.R.; Hugo, J.M.; Norton, K.B. Interrelationships in the cucurbitacin series. Chem. Ind. 1959, 951-952.

41. Sasaki, M.; Murae, T.; Takahashi, T. Synthesis of (+/-)-15-deoxybruceolide and conversion of (-)15-deoxybruceolide into (-)-bruceantin: Total synthesis of bruceantin. J. Org. Chem. 1990, 55, 528-540.

42. Parish, E.J.; Kizito, S.A.; Qiu, Z. Review of chemical synthesis of 7-keto- $\Delta^{5}$-sterols. Lipids 2004, 39, 801-804.

43. Salvador, J.A.R.; Silvestre, S.M.; Moreira, V.M. Catalytic oxidative processes in steroid chemistry: Allylic oxidation, $\beta$-selective epoxidation, alcohol oxidation and remote functionalization reactions. Curr. Org. Chem. 2006, 10, 2227-2257.

44. Salvador, J.A.R.; Silvestre, S.M. Bismuth-catalyzed allylic oxidation using $t$-butyl hydroperoxide. Tetrahedron Lett. 2005, 46, 2581-2584.

45. Salvador, J.A.R.; Silvestre, S.M. Processo para a oxidação alílica de compostos insaturados usando hidroperóxido de $t$-butilo e catalisadores de bismuto. PT Patent 103,211, 15 September 2006.

46. Salvador, J.A.R.; Silvestre, S.M. Faculty of Pharmacy, University of Coimbra, Portugal, 2006, Unpublished results.

47. Samadjar, S.; Becker, F.F.; Banik, B.K. Surface-mediated highly efficient oxidation of alcohols by bismuth nitrate. Synth. Commun. 2001, 31, 2691-2695.

48. Reese, A.L.; McMartin, K.; Miller, D.; Wickham, P.P. Reactions of bismuth triacetate with organic compounds. J. Org. Chem. 1973, 38, 764-768. 
49. Orita, A.; Tanahashi, C.; Kakuda, A.; Otera, J. Highly efficient and versatile acylation of alcohols with $\mathrm{Bi}(\mathrm{OTf})_{3}$ as catalyst. Angew. Chem. Int. Ed. 2000, 39, 2877-2879.

50. Orita, A.; Tanahashi, C.; Kakuda, A.; Otera, J. Highly powerful and practical acylation of alcohols with acid anhydride catalyzed by $\mathrm{Bi}(\mathrm{OTf})_{3}$. J. Org. Chem. 2001, 66, 8926-8934.

51. Carrigan, M.D.; Freiberg, D.A.; Smith, R.C.; Zerth, H.M.; Mohan, R.S. A simple and practical method for large-scale acetylation of alcohols and diols using bismuth triflate. Synthesis 2001, 2091-2094.

52. Mohammadpoor-Baltork, I.; Aliyan, H.; Khosropour, A.R. Bismuth(III) salts as convenient and efficient catalysts for the selective acetylation and benzoylation of alcohols and phenols. Tetrahedron 2001, 57, 5851-5854.

53. Mohammadpoor-Baltork, I.; Khosropour, A.R.; Aliyan, H. A convenient and chemoselective acetylation and formylation of alcohols and phenols using acetic acid and ethyl formate in the presence of Bi(III) salts. J. Chem. Res. (M) 2001, 280-282.

54. Ghosh, R.; Maiti, S.; Chakraborty, A. Facile catalyzed acylation of heteroatoms using $\mathrm{BiCl}_{3}$ generated in situ from the procatalyst $\mathrm{BiOCl}$ and acetyl chloride. Tetrahedron Lett. 2004, 45, 6775-6778.

55. Mohammadpoor-Baltork, I.; Khosropour, A.R. Bi(III) salts as new catalysts for the selective conversion of trimethylsilyl and tetrahydropyranyl ethers to their corresponding acetates and formates. Synth. Commun. 2002, 32, 2433-2439.

56. Mohammadpoor-Baltork, I.; Khosropour, A.R. Efficient and selective conversion of trimethylsilyl and tetrahydropyranyl ethers to their corresponding acetates and benzoates catalyzed by bismuth(III) salts. Mon. Chem. 2002, 133, 189-193.

57. Salvador, J.A.R.; Pinto, R.M.A.; Santos, R.C.; Le Roux, C.; Beja, A.M.; Paixao, J.A. Bismuth triflate-catalyzed Wagner-Meerwein rearrangement in terpenes. Application to the synthesis of the $18 \alpha$-oleanane core and A-neo-18 $\alpha$-oleanene compounds from lupanes. Org. Biomol. Chem. 2009, 7, 508-517.

58. Stephens, J.R.; Butler, P.L.; Clow, C.H.; Oswald, M.C.; Smith, R.C.; Mohan, R.S. Bismuth triflate: An efficient catalyst for the formation and deprotection of tetrahydropyranyl ethers. Eur. J. Org. Chem. 2003, 3827-3831.

59. Khan, A.T.; Ghosh, S.; Choudhury, L.H. A highly efficient synthetic protocol for tetrahydropyranylation/depyranylation of alcohols and phenols. Eur. J. Org. Chem. 2005, 4891-4896.

60. Keramane, E.M.; Boyer, B.; Roque, J.-P. BiBr 3 -catalyzed benzylation of alcohols. Stereochemistry and mechanistic investigations. Tetrahedron 2001, 57, 1917-1921.

61. Kadam, S.T.; Kim, S.S. Mild and efficient silylation of alcohols and phenols with HMDS using $\mathrm{Bi}(\mathrm{OTf})_{3}$ under solvent-free condition. J. Organomet. Chem. 2009, 694, 2562-2566.

62. Carrigan, M.D.; Sarapa, D.; Smith, R.C.; Wieland, L.C.; Mohan, R.S. A simple and efficient chemoselective method for the catalytic deprotection of acetals and ketals using bismuth triflate. J. Org. Chem. 2002, 67, 1027-1030.

63. Bailey, A.D.; Ashvin, R.B.; Tasche, K.K.; Mohan, R.S. Environmentally friendly organic synthesis using bismuth compounds: Bismuth(III) iodide catalyzed deprotection of acetals. Tetrahedron Lett. 2008, 49, 691-694. 
64. Mohammadpoor-Baltork, I.; Kharamesh, B.; Kolagar, S. Efficient deprotection of tetrahydropyranyl ethers by bismuth(III) salts. Synth. Commun. 2002, 32, 1633-1637.

65. Sabitha, G.; Babu, R.S.; Reddy, E.V.; Srividya, R.; Yadav, J.S. A novel, efficient, and selective cleavage of alkyl tert-butyldimethylsilyl ethers using $\mathrm{BiCl}_{3} / \mathrm{NaI}$ system. Adv. Synth. Catal. 2001, 343, 169-170.

66. Boruah, A.; Baruah, B.; Prajapati, D.; Sandhu, J.S. Regeneration of carbonyl compounds from oximes under microwave irradiations. Tetrahedron Lett. 1997, 38, 4267-4268.

67. Pinto, R.M.A.; Salvador, J.A.R.; Le Roux, C. Ritter reaction mediated by bismuth(III) salts: Onestep conversion of epoxides into vic-acylamino-hydroxy compounds. Synlett 2006, 2047-2050.

68. Pinto, R.M.A.; Silva, M.R.; Beja, A.M.; Salvador, J.A.R.; Paixão, J.A. 5 $\alpha$-Acetamido-6 $\beta$ hydroxy-17-oxoandrostan-3ß-yl acetate. Acta Crystallogr. Sect. E 2007, E63, o3321.

69. Pinto, R.M.A.; Silva, M.R.; Beja, A.M.; Salvador, J.A.R.; Paixao, J.A. 6 $\beta$-Acetamido-5 $\alpha-$ hydroxycholestan-3 $\beta$-yl acetate. Acta Crystallogr. Sect. E 2008, E64, o2303.

70. Sanderson, J.; Bayse, C.A. The Lewis acidity of bismuth(III) halides: A DFT analysis. Tetrahedron 2008, 64, 7685-7689.

71. Pinto, R.M.A.; Salvador, J.A.R.; Le Roux, C. Bismuth(III) salts mediated regioselective ring opening of epoxides: An easy route to halohydrins and $\beta$-hydroxy nitrates. Tetrahedron 2007, 63, 9221-9228.

72. Pinto, R.M.A.; Salvador, J.A.R.; Paixao, J.A.; Beja, A.M.; Silva, M.R. 6 $\beta$-Chloro-5 $\alpha$-hydroxy-20oxopregnan-3 $\beta$-yl acetate. Acta Crystallogr. Sect. E 2008, E64, o1420.

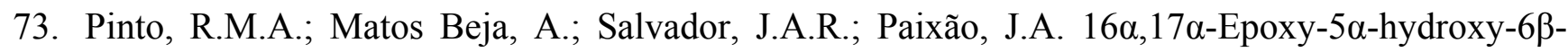
nitrooxy-20-oxopregnan-3 $\beta$-yl acetate. Acta Crystallogr. Sect. E 2009, E65, o1271-o1272.

74. Wabnitz, T.C.; Yu, J.Q.; Spencer, J.B. Evidence that protons can be the active catalysts in Lewis acid mediated hetero-Michael addition reactions. Chem. Eur. J. 2004, 10, 484-493.

75. Keramane, E.M.; Boyer, B.; Rogue, J.P. Reactivity of bismuth(III) halides towards alcohols. A tentative to mechanistic investigation. Tetrahedron 2001, 57, 1909-1916.

76. Carvalho, J.F.S.; Silva, M.M.C.; Sá e Melo, M.L. Highly efficient epoxidation of unsaturated steroids using magnesium bis(monoperoxyphathalate) hexahydrate. Tetrahedron 2009, 65, 2773-2781.

77. Carvalho, J.F.S.; Silva, M.M.C.; Melo, M. Efficient trans-diaxial hydroxylation of $\Delta^{5}$-steroids. Tetrahedron 2010, 66, 2455-2462.

78. Carvalho, J.F.S.; Silva, M.M.C.; Moreira, J.N.; Simoes, S.; Melo, M.L.S. Sterols as anticancer agents: Synthesis of Ring-B oxygenated steroids, cytotoxic profile, and comprehensive SAR analysis. J. Med. Chem. 2010, 53, 7632-7638.

79. Swamy, N.R.; Venkateswarlu, Y. An efficient method for the synthesis of 2,3-unsaturated glycopyranosides catalyzed by bismuth trichloride in Ferrier rearrangement. Synthesis 2002, 598-600.

80. Babu, J.L.; Khare, A.; Vankar, Y.D. $\mathrm{Bi}(\mathrm{OTf})_{3}$ and $\mathrm{SiO}_{2}-\mathrm{Bi}(\mathrm{OTf})_{3}$ as effective catalysts for the Ferrier rearrangement. Molecules 2005, 10, 884-892.

81. Lacey, J.R.; Anzalone, P.W.; Duncan, C.M.; Hackert, M.J.; Mohan, R.S. A study of epoxyolefin cyclizations catalyzed by bismuth trifluoromethanesulfonate and other metal triflates. Tetrahedron Lett. 2005, 46, 8507-8511. 
82. Smith, B.M.; Skellam, E.J.; Oxley, S.J.; Graham, A.E. Highly selective synthesis of oxabicycloalkanes by indium tribromide-mediated cyclization reactions of epoxyalkenes. Org. Biomol. Chem. 2007, 5, 1979-1982.

83. Pinto, R.M.A.; Salvador, J.A.R.; Le Roux, C.; Carvalho, R.A.; Silva, M.R.; Beja, A.M.; Paixão,

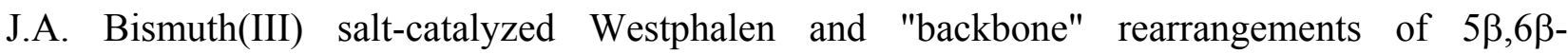
epoxysteroids. Synthesis and structural elucidation of new olefinic 19-nor and 18,19dinorsteroids. Steroids 2008, 73, 549-561.

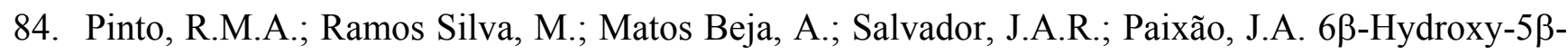
methyl-20-oxo-19-norpregn-9(10)-en-3 $\beta$-yl acetate. Acta Crystallogr. Sect. C 2009, C65, o214-o216.

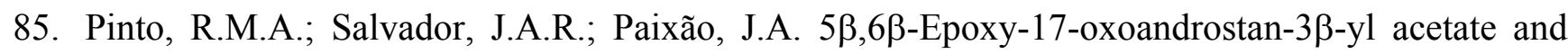

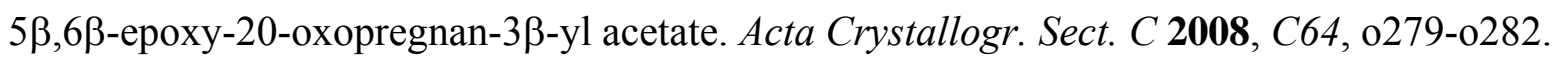

86. Pinto, R.M.A.; Salvador, J.A.R.; Le Roux, C.; Carvalho, R.A.; Beja, A.M.; Paixão, J.A. Bismuth(III) triflate-catalyzed rearrangement of $16 \alpha, 17 \alpha$-epoxy-20-oxosteroids. Synthesis and structural elucidation of new $16 \alpha$-substituted $17 \alpha$-alkyl-17 $\beta$-methyl- $\Delta^{13}$-18-norsteroids. Tetrahedron 2009, 65, 6169-6178.

87. Hanson, J.R. Wagner-Meerwein rearrangements. In Comprehensive Organic Synthesis; Pattenden, G., Ed.; Pergamon Press plc: Oxford, UK, 1991; Volume 3, pp. 705-719.

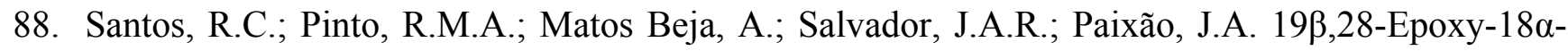
olean-3ß-ol. Acta Crystallogr. Sect. E 2009, E65, o2088-o2089.

89. Repichet, S.; Zwick, A.; Vendier, L.; Le Roux, C.; Dubac, J. A practical, cheap and environmentally friendly preparation of bismuth(III) trifluoromethanesulfonate. Tetrahedron Lett. 2002, 43, 993-995.

90. Vatèle, J.-M. Lewis acid promoted oxidative rearrangement of tertiary allylic alcohols with the PhIO/TEMPO System. Synlett 2008, 1785-1788.

91. Vatèle, J.-M. Lewis acid-catalyzed oxidative rearrangement of tertiary allylic alcohols mediated by TEMPO. Tetrahedron 2010, 66, 913-917.

92. Kiesman, W.F.; Petter, R.C. Lewis-acid catalysis of the asymmetric Diels-Alder reaction of dimenthyl fumarate and cyclopentadiene. Tetrahedron Asymm. 2002, 13, 957-960.

93. Peidro, L.; Le Roux, C.; Laporterie, A.; Dubac, J. $\mathrm{BiCl}_{3}$-catalyzed Mukaiyama-aldol and carbonyl-ene reactions. J. Organomet. Chem. 1996, 521, 397-399.

94. Anderson, E.D.; Ernat, J.J.; Nguyen, M.P.; Palma, A.C.; Mohan, R.S. Environment friendly organic synthesis using bismuth compounds. An efficient method for carbonyl-ene reactions catalyzed by bismuth triflate. Tetrahedron Lett. 2005, 46, 7747-7750.

95. Samajdar, S.; Becker, F.F.; Banik, B.K. Surface-mediated highly efficient regioselective nitration of aromatic compounds by bismuth nitrate. Tetrahedron Lett. 2000, 41, 8017-8020.

96. Samajdar, S.; Becker, F.F.; Banik, B.K. Montmorillonite impregnated with bismuth nitrate: A versatile reagent for the synthesis of nitro compounds of biological significance. ARKIVOC 2001, viii, 27-33.

97. Bose, A.; Sanjoto, W.P.; Villarreal, S.; Aguilar, H.; Banik, B.K. Novel nitration of estrone by metal nitrates. Tetrahedron Lett. 2007, 48, 3945-3947. 
98. Santos, R.C.; Pinto, R.M.A.; Matos Beja, A.; Salvador, J.A.R.; Paixão, J.A. 3-Oxo-18 $\alpha$-olean28,13ß-olide. Acta Crystallogr. Sect. E 2010, E66, o2139-o2140.

99. Pinto, R.M.A.; Salvador, J.A.R.; Le Roux, C.; Paixão, J.A. Bismuth(III) triflate-catalyzed direct conversion of corticosteroids into highly functionalized 17-ketosteroids by cleavage of the C17dihydroxyacetone side chain. J. Org. Chem. 2009, 74, 8488-8491.

100. Oliveto, E.P. Synthesis and degradation of the pregnane side-chain; In Organic Reactions in Steroid Chemistry; Fried, J., Edwards, J.A., Eds.; Van Nostrand Reinhold Company: New York, NY, USA, 1972; Volume 2, pp. 127-236.

101. Le Pera, A.; Leggio, A.; Siciliano, C.; Di Gioia, M.L.; Napoli, A.; Sindona, G.; Liguori, A. A straightforward chemical synthesis of 17-ketosteroids by cleavage of the C-17-dihydroxy acetone side chain in corticosteroids. Steroids 2003, 68, 139-142.

102. Sun, L.; Geng, X.; Liu, L.H.; Jiang, C.G.; Wang, C. Iodine-promoted cleavage of the C-17dihydroxyacetone side chain of corticosteroids in aqueous ammonia water. J. Chem. Res. (M) 2009, 22-23.

103. Avery, M.A.; Woolfrey, J.R. Anti-inflammatory steroids. In Burger's Medicinal Chemistry and Drug Discover: Cardiovascular Agents and Endrocrines; Abraham, D.J., Ed.; John Wiley \& Sons, Inc: New York, NY, USA, 2003; Volume 3, pp. 747-853.

104. McGhie, S.; Strachan, C.; Aitken, S. A review of the use of aqueous hydrofluoric acid in the manufacture of betamethasone. Org. Process Res. Dev. 2002, 6, 898-900.

Sample Availability: Not Available.

(C) 2011 by the authors; licensee MDPI, Basel, Switzerland. This article is an open access article distributed under the terms and conditions of the Creative Commons Attribution license (http://creativecommons.org/licenses/by/3.0/). 